\title{
HISTORIA DEL DESCUBRIMIENTO Y APROVECHAMIENTO DE LAS FUENTES TERMALES EN COSTA RICA
}

\author{
HISTORY OF DISCOVERY AND EXPLOITATION OF THE THERMAL WATER \\ IN COSTA RICA
}

\author{
Guillermo E. Alvarado* y Asdrúbal G. Vargas \\ Centro de Servicio Exploración Subterránea, Instituto Costarricense de \\ Electricidad, Apdo. 10032-1000, COSTA RICA \\ *Autor para contacto: galvaradoi@ice.go.cr
}

(Recibido: 3/02/2017; aceptado: 4/04/2017)

\begin{abstract}
The present work present a chronological account of the discovery, research, and recreational use of the hot and mineral springs of Costa Rica. The descriptions of the investigations carried out have been divided into five periods with a first period called pre-Columbian stage, conquest and Colony until 1755 . The second period is defined from 1755 to 1854, where the first formal descriptions are presented. The third period includes the first scientific investigations made by European scientists $(1855$ - 1873). The fourth period refers to a reduction in the number of researches (1874 - 1954) and the fifth, and last period includes modern research for recreational purposes and applied engineering (1955 - present). The main use of the geothermal energy is for electricity generation, and the mineral and hot springs has been use for tourism, in particular areas associated with volcanic terrains and faults; however, for therapeutic and medicinal use it is still very limited.
\end{abstract}

Keywords: Hot spring, mineral springs, history, discovery, exploitation, use, Costa Rica.

RESUMEN: Se presenta un recuento cronológico del descubrimiento, de las investigaciones, y del aprovechamiento con fines recreativos de las fuentes termales de Costa Rica. La descripción de las investigaciones realizadas se ha dividido en cinco períodos con un primer período denominado etapa precolombina, conquista y colonia hasta 1755. El segundo período considerado desde 1755 hasta 1854 donde se presentan las primeras descripciones formales. El tercer período considerando que incluye las primeras investigaciones científicas a cargo de científicos europeos (1855 a 1873). El cuarto período se refiere a una reducción en el ímpetu de las investigaciones (1874 hasta 1954) y el quinto período que incluye las investigaciones modernas con fines comerciales y aplicados a la ingeniería (1955 - presente). El principal aprovechamiento ha sido la extracción de la energía geotérmica para la generación de energía eléctrica, y el uso de las fuentes termales con fines turísticos en zonas particulares asociadas con aparatos volcánicos; sin embargo, para el uso terapéutico y medicinal es aún muy limitado.

Palabras clave: aguas termales, aguas minerales, historia, descubrimiento, explotación, uso, Costa Rica. 


\section{INTRODUCCIÓN}

En Costa Rica se han identificado casi dos centenares de fuentes minerales frías y fuentes termales (Fig. 1). Mucha de nuestra historia precolombina, colonización y conquista ha estado ligada a las fuentes termales, desde mitos y beneficios presumiblemente medicinales, hasta fines recreativos y, más recientemente, como una guía hacia la búsqueda de los recursos geotérmicos con fines de aprovechamiento de su potencial de generación de energía eléctrica, así como a un geoturismo más organizado; y como un complemento más de la vigilancia volcánica y sísmica.

El descubrimiento, aprovechamiento e investigación de las aguas minerales y termales en nuestro país se puede agrupar en 5 grandes periodos que varían desde las primeras menciones y usos por los amerindios y los primeros colonos, seguido por los primeros análisis (temperatura, composición química y grado de acidez, ubicación, altura, solutos, etc.), descripciones geográficas y geológicas, hasta sus usos con fines recreativos, terapéuticos e industriales; finalizando con la producción de energía eléctrica. Todas estas etapas tuvieron sus altibajos, que serán descritos con detalle a continuación, hasta finalizar con posicionarse Costa Rica como uno de los países en donde el uso, aprovechamiento e ingresos generados por el termalismo recreativo y la generación eléctrica a partir del vapor de un campo geotermal, ha alcanzado posiciones muy altas a nivel latinoamericano e incluso mundial. Cada una de estas etapas será a su vez enmarcada dentro del contexto histórico a nivel nacional y mundial.

\section{ÉPOCA PRECOLOMBINA, CONQUISTA Y COLONIA HASTA 1755}

Con toda probabilidad, los amerindios prehispánicos conocían la ubicación de la mayoría de las fuentes termales en Costa Rica, tal y como lo atestiguan algunas leyendas (Alvarado, 2000) y los restos culturales en sus cercanías (p.ej. Borinquen-Pailas, Las Hornillas de Miravalles, Pocosol de San Carlos, las de Aguas Zarcas - Río Toro, Aguacaliente de Cartago, Valle del Guarco, entre muchas otras (Fig. 1). Sin embargo, resulta extremadamente sorprendente que incluso dentro de la tradición oral, como por ejemplo, en los diccionarios de los idiomas indígenas Chorotega, Boruca y Bribri, no aparece en ninguno de ellos la expresión fuente termal, a lo sumo sötki (nombre en bribri de salitre), o términos chorotegas imprecisos tales como manantial (kita), agua caliente (nimbu natsujmumi, nimbu yatsumu, nimbu yatsujma, pero no necesariamente termal) para diferenciarla del agua fría o sucia (ver Quirós, 2002).

La palabra "pocosol" (en este caso como palabra compuesta o unida) puede ser una concepción del vocablo indígena "pocauzol" es decir "auzol que humea", después se ha convertido en Pozo Azul, nombre dado a varias fuentes sulfurosas (Gagini, 1917) o a las reconocidas quebradas gatas.

Una leyenda indígena que sí refleja claramente el termalismo es la del río Lari que dice lo siguiente:

Al principio el agua era muy caliente y no se podía tomar, por lo que Sibö la sopló para enfriarla (Jara y García, 2003).

Otra leyenda sobre el volcán Poás (Sierra, 1987), denominada "El Sacrificio del Rualdo", deja la tentadora idea de pensar que la salmuera caliente, del lago cratérico del Poás, se formó en época no muy antigua:

Y el rualdo cantó como nunca antes lo había hecho. La maravilla de sus melodiosos trinos vibraron en el ambiente, ahogando el rugido del coloso volcánico. El Poás se enterneció, la dulzura de los cantos hicieron saltar sus lágrimas, llenándose con ellas el cráter en medio de una gran humadera.

El fuego y la lava se extinguieron, ocupando en su lugar una hermosa laguna que cubrió gran parte de la oquedad del volcán.

Así se observa que existe muy poco o nada preservado sobre las fuentes termales y minerales en tiempos prehispánicos. Posterior al arribo de Cristóbal Colón a Cariary (hoy la isla Uvita, al frente de la ciudad de Limón), en 1502, se le 


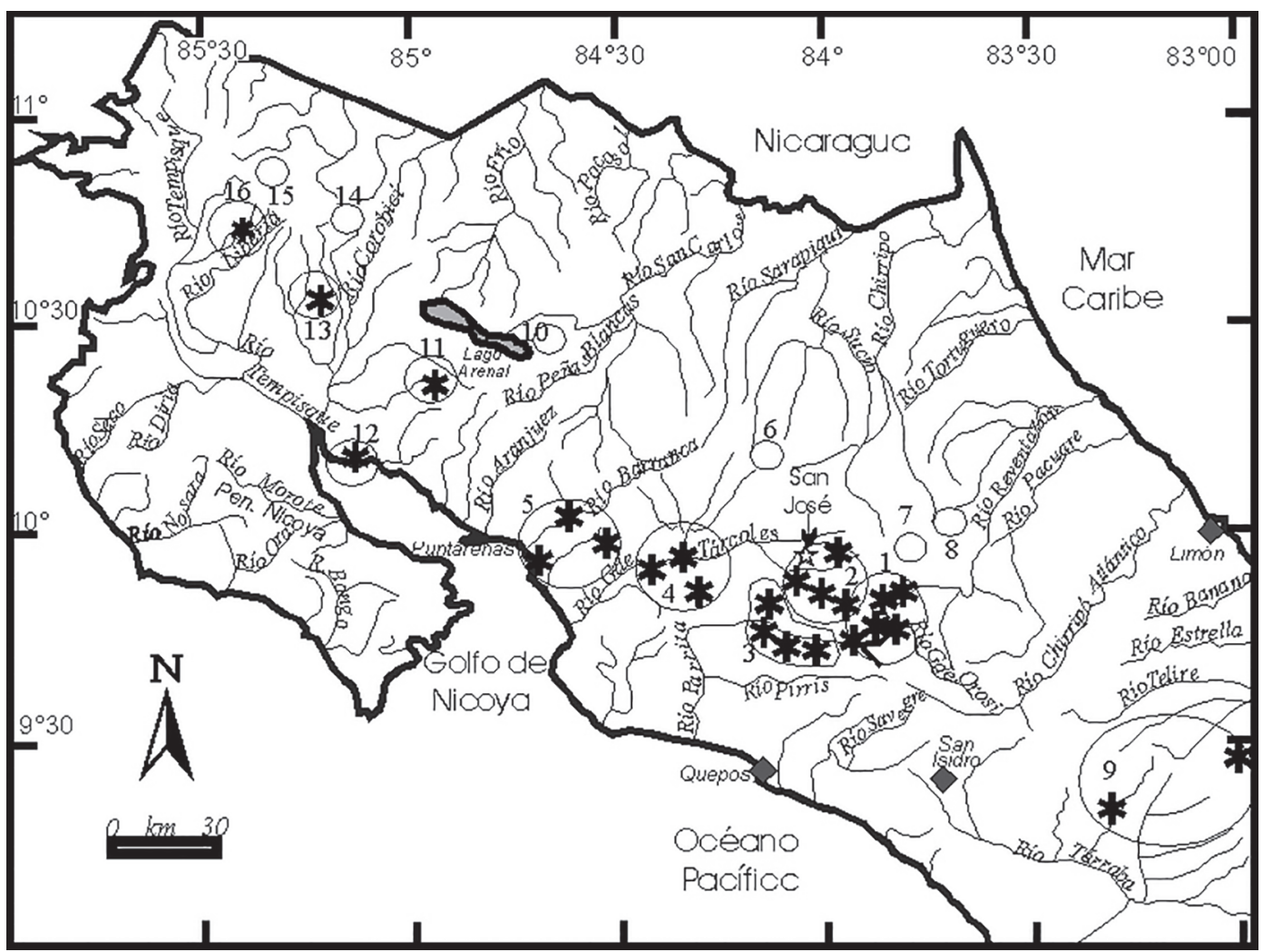

Fig. 1: Principales grupos de fuentes termales distribuidas en 16 grupos.

encomendó a Hernán Sánchez de Badajoz que explorara la "costa rica" de Veragua. Sin embargo, la verdadera conquista del actual territorio nacional se inició después de 1559 , dando como resultado la fundación de la ciudad del Castillo de Garcimuñoz en 1561 por Juan de Cavallón, abandonada y vuelta a fundar varias veces con el nombre de Cartago a partir de 1564 hasta que, en 1575, se ubicó en su sitio actual. En términos generales, entre 1561 y 1573 , aproximadamente, se complementó la conquista y empezó, posterior a ello, la etapa de vida colonial, adquiriendo la provincia Costa Rica su verdadera conformación como territorio político y sociedad propia, llegando a formar parte desde 1568 de la Capitanía General de Guatemala (Meléndez, 1983; Meléndez y Arrea, 2010).

Dentro de este contexto, tenemos la leyenda de Iztarú (Gómez, 1978; citado en Zeledón, 1989) en donde se habla de un río caliente:
Estando en una dura batalla con Guarco, Aquitaba imploró la ayuda de 'Iztarú' sacrificada; del monte más alto salió fuego, ceniza, piedra y cayeron sobre los guerreros de Guarco que huyeron. Del costado del monte salió un riachuelo que se convirtió en agua caliente destruyendo los palenques de Guarco.

La anterior leyenda ubica temporalmente en el inicio de la Conquista (cerca de 1560), pues Vásquez de Coronado conoció a Guarco, y se puede interpretar como una corriente de agua y barro caliente conocida como lahar, quizás producto de una erupción a través de un lago cratérico (Alvarado, 2000).

También se tiene la leyenda de "Las Cuatro fuentes", para referirse a las fuentes termales del valle de Ujarrás. Sucedió una vez que "cuando 
los hombres se habían apartado un poco de sus costumbres católicas", un pequeño cerro cercano comenzó a agitarse y a despedir llamas de grandes proporciones. Dado que las personas pensaron que la virgen estaba disgustada, el padre Guardián ordenó una romería para bautizar el cerro con agua bendita. Las llamas se aplacaron, pero en cambio brotaron cuatro fuentes de agua (Mata, 1930). El padre Guardián era el presbítero que estaba al momento de la erupción del Irazú de 1723 (De la Haya, 1723), por lo que se podría ubicar la supuesta formación de dichas fuentes alrededor de dicho año, quizás en asocio con algún terremoto importante. Aunque Peraldo y Montero (1994) mencionan varios eventos que afectaron a la ciudad de Cartago alrededor de 1723 (p.ej., $1715,1718,1727$ - 1728), todos estos los asocian con posibles fuentes lejanas y no con un fallamiento local.

Sin embargo, sobre la percepción que tenían los amerindios costarricenses referente a las aguas termales, no es del todo clara, tal y como se desprende de los pocos documentos de los primeros exploradores extranjeros en Baja Talamanca. Por ejemplo, von Frantzius (1873) menciona que los indios mestizos utilizaban la fuente termal del río Tskui con fines medicinales (laxante, enfermedades de la piel y úlceras crónicas). Pittier (1895) también describe la misma fuente termal, muy frecuentada por las tribus vecinas, pero que las burbujas con olor a dióxido de azufre $\left(\mathrm{H}_{2} \mathrm{~S}\right)$ eran para los bribris palabras del diablo (bi o Bë'), que solo los médicos podían comprender. Por ello, previo a comenzar una temporada de baños termales, el indio se iba muy lejos al valle de Tararia a visitar a uno de estos grandes personajes y hacerle regalos para que consienta en venir a Djiribá (agua caliente) para conferenciar con Satanás, y asegurar la curación del enfermo. La palabra Djiribá, sin embargo, no aparece en el diccionario bribri (Jara y Murillo, 2003), ni en otros consultados de idiomas prehispánicos vecinos.

De igual modo, en el diario de unos religiosos alemanes en Talamanca, reproducido por Quesada (2001, p. 427, 429) y por Barrantes (2009, p. 501), se menciona que en 1900 encontraron una fuente termal en la margen izquierda de la quebrada Petzéi, en donde los indios creían que quien metiese una mano o un pie dentro, contraería calentura.

Durante más de un cuarto de milenio, Costa Rica formó parte del imperio Hispánico, que terminó por conformar una sociedad, en su mayor parte, centrada como una isla o montaña aislada. El poblador tenía un carácter introvertido puesto que la ausencia de grandes recursos económicos, el aislamiento y una vida basada fundamentalmente en una agricultura de subsistencia, moldearían los rasgos que llegaron a caracterizarlo (Meléndez, 1983). Por ello, esta fue una época oscura con ausencia de informes o documentos sobre el termalismo, en donde muchas de sus tradiciones orales y leyendas de los amerindios se perdieron en el tiempo y los colonizadores y colonos estaban más preocupados por la sobrevivencia, que por documentar este tipo de manifestación termal. Esta situación se reproducía con mayor o menor grado en el resto de América Central, en una época en donde se estaba dando el acomodo socio-cultural, económico y político en todo el continente Americano. Es por ello que la escaza información sobre el tema en los primeros años de la época de la conquista y la colonia no permite un registro continuo ni una descripción completa, pero pese a ello se trató de hilvanar una historia relativamente fluida.

\section{LAS PRIMERAS REFERENCIAS PROPIAMENTE DICHAS: 1754 A 1854}

Esta etapa está caracterizada por las primeras referencias por escrito de las fuentes termales en Costa Rica, iniciando con la primera mención en 1754 cuando la señora Francisca de Bonilla se acercaba al final de su vida, quien declaró como bienes suyos "una hacienda de cañaveral en el Valle de Aserrí, en el paraje nombrado San José de Salitral", debido a las aguas termales que existían allí (www.desamparados.go.cr-Museo La Carreta). En los documentos no queda claro, sin embargo, si ya se citaba la presencia de manantiales minerales desde mediados del siglo XVI en los terrenos conocidos como "El Salitral" o si tan solo se menciona una propiedad mayor, en donde allí se encontraban, llamada "Nuestra Señora del 
Rosario". Este primer documento es seguido por el del año 1756 cuando dos misioneros mencionan en sus crónicas la existencia de un yacimiento de sal, asociado a una fuente termal, ubicada al norte de Esparza, en dirección hacia la cordillera (von Frantzius, 1873).

Posteriormente, durante la época colonial y la fundación de la ciudad de Cartago como capital, surge la información sobre la fuente termal de Aguacaliente de Cartago. Al parecer fueron redescubiertas y resarcidas por su valor curativo en 1782 por el Dr. Pedro Jiménez (Castro y Castro, 2005), aunque también se le atribuyen a un médico inglés, según consta en los archivos de la Real Audiencia de Guatemala (S.a., 1886).

En 1784, don Juan Flores, Teniente Coronel de los Reales Ejércitos, Sargento Mayor del Regimiento fijo de Guatemala y Gobernador accidental de la entonces provincia Costa Rica, hizo constar que (S.A., 1886):

después de descubierta en el Barrio Agua Caliente, el agua mineral, construyó dos depósitos de cal y canto, uno para el agua que debe beberse y otro para el Baño: una pared de cantería para detener la entrada del Río, una galera de madera de zedro (sic) cubierta de teja y un puente que facilita el paso del rio á (sic) dicha agua.

Tanto S.A. (1886) como Fernández (1889, reproducido en 1975 , p. 207) mencionan igualmente que el gobernador provisional don Juan Flores en 1784 fue residenciado por Luis Blanco de Sasido, corregidor de Nicoya. En el juicio de residencia consta que compuso y empedró las calles de Cartago y:

Quando (sic) el Residenciado no hubiera hecho otro servicio al Público que la fábrica del Puente: los dos depósitos de la Agua Mineral, de Marte, ó (sic) como comúnmente se llama Agua Thermal: la pared para atajar el Río, y la fábrica de la casa, ó Galera, para el abrigo de los valetudinarios, merece por ésto, que se eternice su nombre y los conciudadanos de Cartago cada día deben rendirle gracias.
Por todo lo referido merece que se le dé el título de Descubridor de esta singular Medicina, haunque muchos años antes se havia descubierto, por un Médico Inglés, pero ya fuese por la decidia de las gentes, ó (sic) porque se olvidase su vso, estavan obscurecidas estas Aguas, y así en tiempo del Residenciado tuvieron su segundo descubrimiento, y aplicó todo su desvelo en su uso, con -razón puede darse el titulo de Descubridor.

A finales del siglo XVIII, la medicina seguía en nuestro país en manos de empíricos y curanderos, amén de unos pocos facultativos, por lo que las fuentes termales de Aguacaliente de Cartago tuvieron un papel importante debido a las curas que se le atribuían (Blanco, 1989).

En el oficio del 7 de abril de 1804, nuevamente se menciona en el informe enviado por don Tomás de Acosta, sobre el puerto de Punta de Arenas (sic) y la provincia Costa Rica (Fernández, 1907, Tomo X, p. 305; Trejos, 1959 , p. 129), la probable composición y temperatura relativa del agua termal de la fuente de Aguacaliente:

A menos de una legua de esta ciudad cabecera se ve un manantial de agua mineral que por sus señales y efectos se conoce ser de fierro y se le da el nombre de Hervedero, porque sale de la tierra hirviendo y tan caliente que mientras se reza devotamente un credo se cuecen los huevos que se ponen allí.

El inglés John Hale (1826) comenta sobre la fuente termal de Aguacaliente de Cartago:

A una milla al sudeste de la ciudad [Cartago] hay una fuente de agua mineral caliente, fuertemente impregnada de hierro, cuyas piedras están incrustadas de lo mismo. Habiendo asado una en el fuego, raspé el mineral que se adhirió al imán. Esta fuente tiene un fuerte olor sulfúrico y me inclino a creer que posee grandes virtudes y que algún día atraerá sin duda muchas gentes a Cartago y a su hermosa y saludable vecindad. 
Después agrega lo siguiente:

En la vecindad de San José hay otra fuente de agua mineral caliente [posiblemente Salitral de San Antonio de Desamparados] que difiere de la de Cartago. En los contornos de este manantial la tierra contiene una sal semejante al alumbre y los ganados de las vecindades vienen a chuparla. También hay allí vetas de una tierra que parece jabón al frotarla con los dedos. El conjunto de este lugar procuraría un gran placer a una mente científica.

Resulta importante recordar que el 13 de marzo de 1843, la Casa de Enseñanza de Santo Tomás (establecida el 24 de abril de 1814) se convierte en universidad y que para 1839, el Poder Ejecutivo ordenó establecer un curso de medicina, por decreto del entonces Jefe de Estado Juan Mora Fernández. El 15 de setiembre de 1850 (29 años después de la independencia) se crea la Facultad de Medicina de Costa Rica, siendo Presidente de la República don Juan Rafael Mora Porras (Blanco, 1989).

Para 1854, don José María Castro Madriz, quien había sido Presidente de la República entre 1847 y 1849 , obtuvo la propiedad de "El Salitral", que era parte "potrero y monte" (www.desamparados.go.cr-Museo La Carreta).

Como se desprende de lo anterior, los españoles y primeros colonos trataron de aprovechar las propiedades de las fuentes termales de una manera muy escueta, dejando un gran vacío de conocimiento en más de 200 años de dominación.

\section{LAS PRIMERAS INVESTIGACIONES CIENTÍFICAS, CATÁLOGOS Y USOS MEDICINALES: 1855 - 1873}

Con la apertura de Costa Rica al mundo exterior, empezaron a hacer su ingreso al país personas de diversos países, sobre todo de Europa y Sudamérica, de diversas profesiones, incluyendo científicos, viajeros y hasta aventureros, alabando en la mayoría de los casos a esta sociedad y reconociendo las condiciones idílicas y patriarcales de la vida de ese entonces. Se dio, además, un incremento de las obras públicas, incluyendo el empedrado de las calles, facilitando la movilidad y el redescubrimiento de nuestro territorio, dándolo a conocer por escrito, no solo en nuestro medio, sino a nivel internacional (Meléndez, 1983).

Las convulsiones en que se vio envuelta Europa sobre todo a partir de 1848, fueron el motivo que atrajo numerosos inmigrantes del norte de Europa. Se realizan las primeras descripciones geológico-mineralógicas y geoquímicas generales, su temperatura, así como los primeros catálogos propiamente dichos. Se habla por primera vez de los posibles aspectos curativos de alguna de las fuentes termales, principalmente la de Aguacaliente de Cartago, mencionadas por el irlandés Thomas Francis Meagher y los alemanes Karl Hoffmann y Wilhem Marr, entre muchos otros.

Por su parte, el investigador alemán von Frantzius, con su afán de explorador, visitó en el año 1855 la fuente termal de Aguacaliente de Cartago. Meléndez (1976, p. 92) incluye y atribuye la descripción realizada a K. Hoffmann el 5 de mayo de 1855, como parte de la visita que realizó al volcán de Cartago (Irazú), pero Hilje (2008) reinterpreta que este documento en realidad corresponde en su autoría a von Frantzius:

Para no desaprovechar el tiempo precioso, fué (sic) concertada y realizada una excursión a la fuente termal de la aldea Aguacaliente, distante de Cartago, una media hora (una media hora: tres cuartos de milla alemana). La fuente misma está más baja que Cartago, que según Bonnet está a 6500 pies ingleses, y situada al pie de una cadena de colinas de apenas 2000 pies de elevación, compuesta de piedra calcárea con muchos pequeños cristales de cuarzo y oxihidrato de hierro. La fuente se derrama en un recipiente de cuatro pies de diámetro y sólo (sic) dos de profundidad hecho por ella misma lavando la roca. La temperatura es de $40^{\circ} \mathrm{R}$. $\left[50^{\circ} \mathrm{C}\right.$ ] con una temperatura del aire de $19^{\circ} \mathrm{R}$. $\left[23,7^{\circ} \mathrm{C}\right]$, el sabor amargo salado algo astringente; en la orilla y el fondo del recipiente deposita el agua un lodo moreno rojizo que contiene hierro. 
Meagher (1859-60) agrega sobre dicha fuente:

Más allá de los "potreros" se veía las montañas bajas de Agua Caliente, así llamadas por el manantial de agua tibia que brota a sus pies, a milla y media de la ciudad, en una gruta de cuarzo y óxido de hierro. El agua de esa fuente es amarga y astringente. La aristocracia enferma de la vecindad la frecuenta y es eficaz, sobre todo en los caso de gota y reuma.

Durante su estadía en Costa Rica en el año 1853 el viajero Marr escribió cartas a sus amigos en Alemania, cuyos relatos se publicaron más tarde en el periódico Freischütz, de Hamburgo y posteriormente en un libro diez años más tarde titulado Reise nach Central-Amerika. Con respecto a su estadía en Cartago señala lo siguiente:

Al pie de las cordilleras hay un pueblo, un río y una fuente de aguas termales. Los tres se designan con el nombre de Agua Caliente. La temperatura de esta agua es de unos $54^{\circ} \mathrm{R}\left[67,5^{\circ} \mathrm{C}\right]$. Es ferruginosa y tiene un ligero sabor a ácido carbónico. Dicen que posee una maravillosa virtud curativa en los casos de úlceras e inflamaciones. Un anciano que pasó a mi lado arreando una vaca me dijo que el agua de la fuente era venenosa. Al oír esto me bebí dos vasos grandes en un cubilete de caucho sin tomar ninguna precaución, para saber si Dios había permitido que hubiese un manantial envenenado en Costa Rica, aunque en Europa tolera tantas "recetas médicas" inofensivas. Até mi caballo en el tronco desmedrado de un tamarindo, me tendí al borde del manantial, encendí un cigarro y me puse a aguardar la muerte (Marr, 1863).

La toma de temperatura de Marr en 1853 y de von Frantzius en 1855 al parecer corresponde con las primeras medidas de temperatura de una fuente termal en Costa Rica.

Wagner (1862) menciona en el Miravalles las hornillas humeantes al pie del lado sur y la permanente actividad de cráteres de lodo en las cercanías de fuentes termales.

Pero Alexander von Frantzius fue sin lugar a dudas, uno de los naturalistas alemanes que realizó un aporte extraordinario a la investigación de las fuentes termales. Durante una visita de nuevo al valle de Orosi próximo a 1860 , describe las características de varias fuentes termales. Una de ellas cercana al río Navarro (von Frantzius, 1860):

A unos cien pasos antes de llegar al puente que está sobre el río Navarro, se ve muy cerca del camino, al pie de una ladera de montaña, una masa calcárea en forma de estalactitas, de donde nace una fuente que brota con fuerza... Esta es una de tantas fuentes de agua caliente que se encuentran especialmente en el sur de Cartago y también en otros lugares de Costa Rica. La fuente cálida de Navarro cuya agua clara es totalmente insípida y que a juzgar por sus sedimentos parece contener una cantidad considerable de cal, tiene una temperatura de $25,8^{\circ} \mathrm{R}\left[=32,2^{\circ} \mathrm{C}\right]$.

Seguidamente visitó la fuente termal de Orosi:

la fuente tibia que dista solo unos cien pasos del convento....La temperatura de esta fuente llega a $27,6^{\circ} \mathrm{R}\left[=34,5^{\circ} \mathrm{C}\right] \mathrm{y}$ es altamente bienhechora para el cuerpo.

Además, logró observar otras fuentes durante una excursión a los valles de los ríos Macho y Purizil en compañía del señor Lucas Alvarado:

Antes de hubiéramos llegado al fin de las llanuras nos enseñó un manantial de agua caliente, que brota en una hondonada de este suelo plano. A una distancia de 50 pasos, poco más o menos, ya notábamos un ligero olor de ácido sulfúrico. El agua hervía con notable desprendimiento de gases, a una temperatura de $41,2^{\circ} \mathrm{R}\left[51,5^{\circ} \mathrm{C}\right]$. Es casi insípida, pero el sedimento de cristales depositado en las piedras bañadas por esta agua revela 
que contiene una pequeña cantidad de sal de cocina. Las piedras que se encuentran siempre debajo del agua están cubiertas por una "oscilatoria" verdeoscura. Esta alga de finísimos cabellos parece que no falta en ninguna de las fuentes termales saladas que he encontrado en Costa Rica.

En marzo de 1860 exploró el cráter activo del Poás, estimó las dimensiones de la laguna (seis manzanas), analizó las características físicas y químicas del agua, midiendo por vez primera la temperatura in situ del agua caliente del cráter $\left(39,1^{\circ} \mathrm{C}\right)$.

Según el Dr. Henri Pittier, el doctor von Frantzius es el autor de la mejor descripción que se había hecho de los volcanes en Costa Rica hasta ese entonces (Fig. 2). En el año 1861, von Frantzius publica en Alemania un artículo denominado Beiträge zur Kenntniss der Vulkane Costaricas (Aportes al conocimiento de los volcanes en Costa Rica), con la descripción del ascenso y estadía a varios cráteres volcánicos de Costa Rica e incluye observaciones sobre fuentes termales, fumarolas y lagunas cratéricas.

Von Frantzius (1861, p. 330) describe que alrededor de la cima del volcán Rincón de la Vieja, hay una cantidad de solfataras, llamados hornillos y en las laderas del volcán Miravalles se encuentran fuentes sulfurosas calientes, con vapores de azufre. Además, como parte de las experiencias obtenidas durante el ascenso al cráter del volcán Poás, dicho investigador señala que analizó y midió la temperatura del agua del cráter.

Bajé hasta la orilla y analicé el agua turbia y lechosa, que tenía la apariencia de lejía y en cuya superficie flotaba una masa polvorosa negro-grisácea,....El agua, cuya temperatura era de $31,1^{\circ} \mathrm{R}\left[38,8^{\circ} \mathrm{C}\right]$, tenía un sabor ácido penetrante.

Además, von Frantzius no identificó un desagüe evidente para la laguna del volcán Poás. No obstante, fue informado por Miguel Alfaro sobre el interesante hecho de que él encontró en 1846 agua ácida en el río Agrio, un afluente del río Toro Amarillo, el cual él mismo había descubierto en el año 1827 (von Frantzius, 1861,

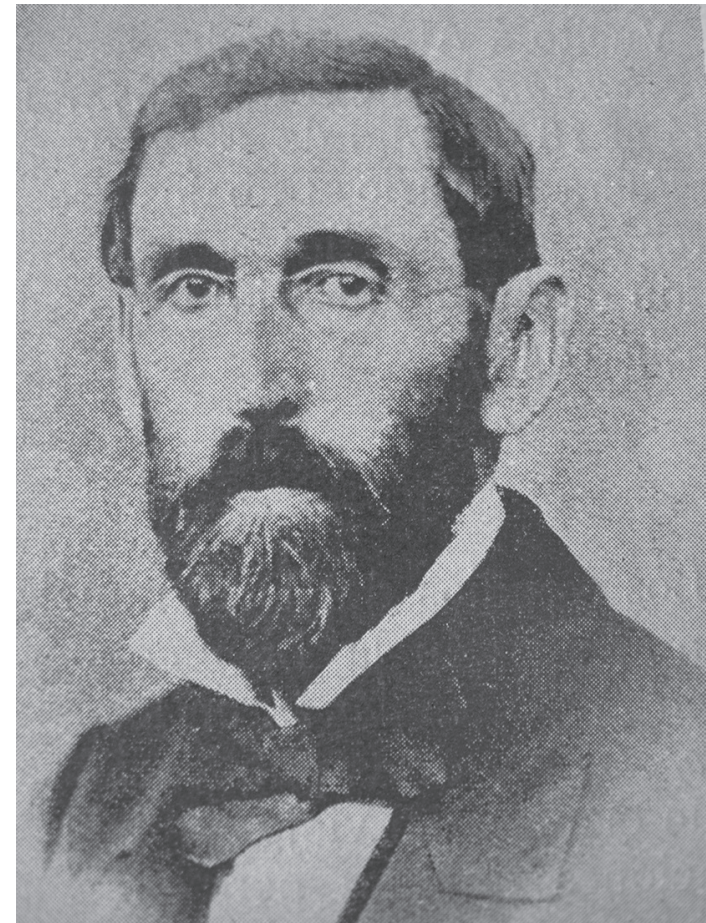

Fig. 2: Alexander von Frantzius (1821 - 1879), quien realizó los primeros catálogos y el primer libro de las fuentes termales de Costa Rica.

p. 337). De igual modo, sus dos trabajos sobre fuentes termales, ambos bajo el mismo título Die warmen Mineralquellen in Costa Rica ("Las fuentes termominerales en Costa Rica"), aunque publicados en años y con enfoques algo diferentes (von Frantzius, 1862a, 1873), constituyen los primeros dos catálogos de fuentes termales de Costa Rica, en donde, en forma avanzada para su época, no solo presenta los primeros análisis químicos, sino que además habla de sus posibles orígenes: a) asociadas con volcanes activos o dormidos, b) en ambientes de grandes bloques tectónicos o fallados y c) asociados con rocas intrusivas. Dichos conceptos aún son válidos. Adicionalmente, von Frantzius (1862b) publica el primer libro sobre las fuentes termales de Costa Rica (Vargas y Kussmaul, 2015) (Fig. 3). Además, comenta que dichas fuentes se podrían explotar más con fines terapéuticos, industriales y para la obtención de sal para el ganado (ver Vargas y Alvarado, 2007). 
Algunas menciones escuetas sobre aguas termales son realizadas, en denuncios de minas en la región de Abangares. En el año de 1861, se menciona en el diario oficial de Costa Rica, el denuncio de una veta mineral, en cuya localización se menciona la presencia de aguas termales (Gaceta Oficial de Costa Rica, N. ${ }^{\circ} 11,1$ de junio de 1861):

Por auto proveido en este juzgado a las once de la mañana de este día, se admitió a los Sres. Rafael Alvarado, José Rojas, Leandro Quesada, Ramón Zamora, Jesús Paniagua y Procopio ambos, vecinos de la Villa de San Ramón de los Palmares, el denuncio de una veta mineral de oro y plata, que han descubierto al este de la Villa de las Cañas, hacia las cabeceras del río Abangares, quedando al oeste usos salitrales y pilas de agua caliente. El rumbo de dicha veta es de Norte a Sur las personas que tengan algún derecho a la mina denunciada, comparezca a legalizarlo dentro del término que señala la ley. Judicatura de Hacienda. San José. Mayo 24 de 1861, Juan R. Mata; Indalecia Chaves - P. Fonseca.

Otro naturalista alemán que visitó Costa Rica en la segunda mitad del siglo XIX, fue Karl von Seebach, quien en 1864 describió el viaje que realizó por Guanacaste y la exploración de los volcanes Rincón de la Vieja y Miravalles y sus manifestaciones secundarias (hornillas, solfataras y fuentes termales). Esta descripción fue publicada junto con un mapa de la parte Norte de Costa Rica en una famosa revista de geografía de Alemania (von Seebach, 1865a) en el año de 1865. Posteriormente, fue traducido por E. $\mathrm{v}$ de Wiepking y publicado en Costa Rica por Meléndez (1974). Más adelante describió este mismo naturalista su ascenso al volcán Turrialba (von Seebach, 1865b).

En el año de 1865 el presidente de la República, José M. Montealegre, le encomendó a Luciano Platt, que realizara un análisis químico del agua de cuatro manantiales de agua mineral conocidos por el nombre de Salitral de Santa Ana, Hervidero de Aguacaliente, Pozo Tibio y

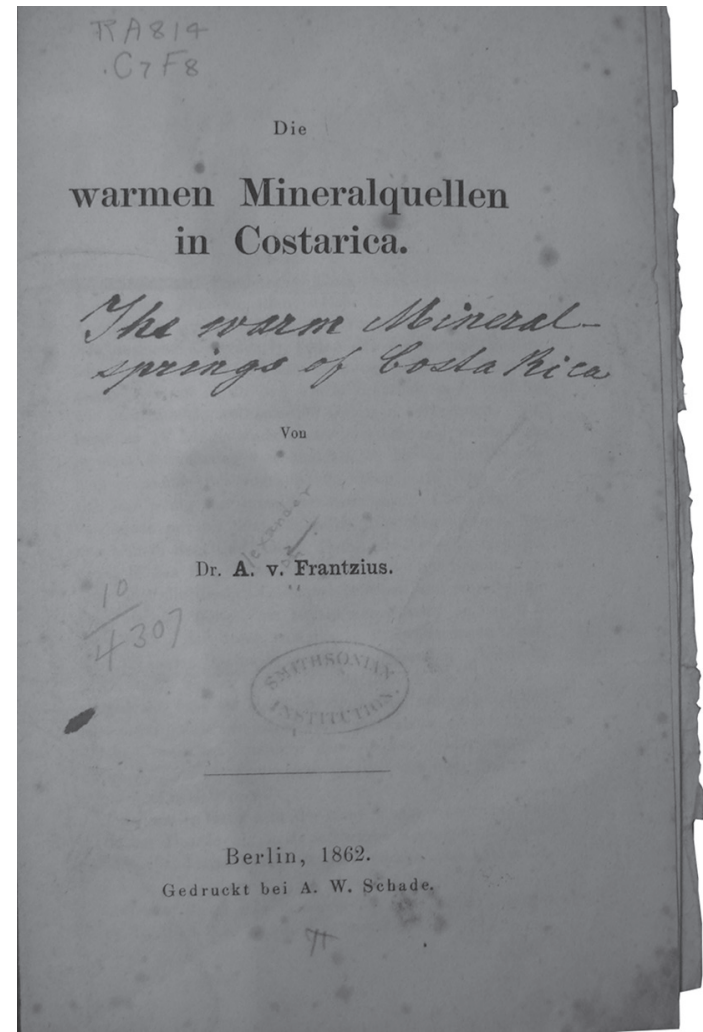

Fig. 3: Primer libro de fuentes termales de Costa Rica publicado por Alexander von Frantzius en 1862.

Hervidero de Orosi, debido a que tenían propiedades medicinales y a su ubicación cercana a los centros de población de Cartago y San José. Platt (1865) describe someramente las condiciones geológicas dentro de las cuales brota el agua de los manantiales, midió la temperatura y analizó químicamente el agua, cuantificando los componentes principales. Con toda probabilidad estos son los primeros análisis químicos de las fuentes termales y minerales realizados en Costa Rica. En el cuadro 1 se comparan varios compuestos identificados en el agua, según los datos aportados en Gaceta Oficial.

Platt comenta que la fuente de Salitral de Santa Ana era utilizada por los vecinos por sus efectos medicinales, lo mismo la de Pozo Tibio y Hervideros de Orosi, esta última encerrada en un estanque de "cal y canto" por el Dr. Lucas Alvarado, quien aducía su importancia médica. Por ejemplo, una de las enfermedades que supuestamente curaba el agua 
Cuadro 1

Concentraciones químicas en gramos de varias fuentes minerales frías y termales (Platt, 1865).

\begin{tabular}{|c|c|c|c|c|}
\hline Salitral de Santa Ana & Herv. Agua Caliente & Pozo & Tibio, Orosi & Hervidero Orosi \\
\hline Temperatura ${ }^{\circ} \mathrm{C}$ & Ambiente $\sim 20^{\circ} \mathrm{C}$ & 55 & 17 & 44 \\
\hline \multicolumn{5}{|l|}{ Compuesto } \\
\hline Sulfato de cal & 0,2 & 0,3 & 0,9 & 0,3 \\
\hline Sulfato de potasa & - & - & - & 0,2 \\
\hline Sulfato de magnesia & 0,3 & 0,1 & 0,1 & - \\
\hline Nitrato de sosa & - & - & 0,2 & - \\
\hline Carbonato de cal & 0,6 & 0,4 & - & - \\
\hline Carbonato de magnesia/o & 0,2 & 0,1 & - & - \\
\hline Carbonato de hierro & 0,1 & 0,2 & - & - \\
\hline Cloruro de potasio y sodio & 0,8 & 0,7 & 1,1 & 0,4 \\
\hline Cloruro de calcio & - & - & 0,3 & 0,3 \\
\hline Cloruro de magnesio & - & 0,2 & 0,1 & - \\
\hline Substancia orgánica & 0,1 & - & - & - \\
\hline Total & 2,3 & 2,0 & 2,7 & 1,2 \\
\hline
\end{tabular}

del Pozo Tibio era el güegüecho o coto, o conocido técnicamente como bocio, que es un aumento del volumen de la tiroides a expensas del tejido propiamente tiroideo. Platt se dio a la tarea de buscar el yodo en el agua de la fuente ya que el bocio endémico se decía que es producido por un déficit de yodo. Sin embargo, no encontró yodo y en su lugar pensó que quizás sea el contenido de "cal" de las aguas, la responsable de poder curativo. Platt (1865) igualmente menciona que la fuente termal de Orosi fue utilizada por los primeros colonos:

subiendo la colina al Sur de la antigua iglesia de la misión de Orosi, se halla primero el Pozo Tibio, y un poco más arriba las ruinas de una construcción española edificada con el objeto de encerrar las aguas de la fuente.
Agrega además consideraciones terapéuticas:

Las aguas termales deben usarse, sea para baños, sea para beber, en el lugar mismo en donde nacen. Convienen sobre todo, á las constituciones linfáticas y escrofulosas, a la curación de las enfermedades del cutis, sífilis constitucional y para las heridas de armas de fuego, etc.

Von Frantzius (1869) menciona que en el valle del Térraba y a la entrada al Golfo Dulce cerca de Punta del Banco existen fuentes termales, aunque no las describe.

En 1873, von Frantzius publicó nuevamente un artículo titulado las Fuentes termominerales en Costa Rica, en la revista Neues Jahrbuch für Mineralogie, Geologie und Palaentologie (Nuevo 
anuario para mineralogía, geología y paleontología). Este artículo describe por primera vez los ambientes geológicos donde ocurren las fuentes termales, los principales compuestos químicos del agua en las fuentes y presenta veintiocho fuentes termales con su ubicación espacial en Costa Rica. Además incluye datos químicos de un análisis de la fuente de Aguacaliente de Cartago y valores de temperatura de varias de las fuentes investigadas.

\section{EL DECLINAR DE LAS INVESTIGACIONES: 1874 - 1954}

Este periodo resulta algo extraño y hasta antagónico en lo que corresponde a los sistemas educativos y de desarrollo a nivel nacional. Mientras que por un lado existe un repunte en reformar la enseñanza en Costa Rica, lo que propició la apertura de las primeras instituciones de enseñanza media, la contratación de profesores suizos y la creación de un Instituto Meteorológico Nacional, por el otro lado, el Presidente de la República de ese entonces, don Bernardo Soto, conjuntamente con su Ministro de Instrucción Pública, don Mauro Fernández, clausuran en 1888 la Universidad de Santo Tomás con la intención de fomentar y reforzar la enseñanza básica mediante el traslado de recursos a los niveles más necesitados y rentables. Dicha medida fue duramente criticada, pese a que eran personas de gran capacidad y visión y son considerados los reformadores de la enseñanza en Costa Rica (Alvarado y Morales, 1989; Blanco, 1989; Meléndez, 1983). De igual modo, a partir de 1870 se inicia la inversión extranjera en áreas claves de la economía nacional, por lo que se dan los pasos para la industrialización, además de profundos cambios en los sectores sociales laborales y de transporte, aunado al crecimiento demográfico del Valle Central. Esto estimula, por un lado la sociedad económica capitalista y, por el otro extremo, la pobreza producto de la propia existencia de la primera, situación que se mantiene hasta por lo menos 1930 (Meléndez, 1983; de la Cruz, 2005).

Pese a que muchas de las ciencias naturales se vieron reforzadas con la reestructuración de la enseñanza media, se tiene que con la última contribución de Alexander von Frantzius en 1873 sobre las fuentes termales y de otros investigadores extranjeros, se genera una merma substancial en las investigaciones de las fuentes termominerales en Costa Rica. Aunque se tienen algunos trabajos aislados, estos aportan poco a lo ya conocido.

Así tenemos que Attwood (1882, p. 334) menciona que en el valle de Orosi y cerca del poblado existe una quebrada llamada "Río Agua Caliente", y que similares fuentes termales se observan en otros lugares cercanos, del tipo sulfurosas y conteniendo cantidades variables de cloruro de sodio, con carbonatos de soda y magnesio, óxidos de hierro, así como ácidos carbónicos y sulfurosos en forma de gases.

A inicios de 1882, Monseñor Augusto Thiel visita la ermita del barrio San Francisco o Aguas Calientes, también conocida como iglesia de San Francisco del Hervidero, tal y como aparece en el libro de matrimonios de Cartago de 1892 (Herrera, 2009). Unos pocos años después, para el 26 de diciembre de 1885, se aprobó el contrato de los baños termales por la ilustre corporación municipal del cantón Central de Cartago con los señores Roberto A. Crespi y León de Gatskoffsky, concediéndoles por el término de 49 años el uso exclusivo de las aguas termales de Aguacaliente de Cartago. El contrato se traspasó a la sociedad anónima Bella Vista, aprobado por decreto un 19 de febrero de 1886 (S.A., 1886; La Nación, 1959). Este vendría a ser el primer contrato oficial para el uso de aguas termales en Costa Rica con fines turísticos y terapéuticos [En el portal del Sistema Nacional 
de Bibliotecas (www.sinabi.go.cr) aparece una fotografía antigua del alemán Otto Siemon, que según parece fue tomada entre 1873 y 1874, en donde se muestra a lo lejos una edificación atribuible en la leyenda (pie de la fotografía) al balneario de Aguas Termales de Orosi. Al parecer es una mala interpretación de la fotografía por parte del afamado historiador don Carlos Meléndez, dado que el primer balneario fue el de Aguacaliente (construido en 1886) y el balneario de Orosi no aparece hasta 1960]. Ello vendría a cristalizar el 27 de abril de 1886 con el inició de la construcción del hotel de madera por parte de la compañía Bella Vista, llamada en ese entonces Baños Aguacaliente o Baños Termales de Aguacaliente. El Ing. G. H. Lathan estaba ligado a dicha compañía. Se construyó sobre la margen derecha del río un hermoso edificio con baños muy confortables, tinas limpias y desinfectadas, habitaciones para pasajeros, salas de refresco, cantina, salones de lectura y una amplia plataforma con su balaustrada a unos tres metros sobre el nivel del río y una azotea con una espléndida vista del Irazú y otros lugares del valle de Cartago. Se estableció además un tranvía de vapor que unía a la antigua capital con el balneario, pero después este medio de transporte fue suprimido por dificultades de la empresa. Para el 10 de junio de 1886, quedó constituida la junta directiva de la compañía Bella-Vista, según se lee en el diario oficial La Gaceta. Se comentaba en ese entonces que dichas fuentes e instalaciones podían llegar a tener un gran interés turístico, en particular para los estadounidenses en la época de invierno (S.A., 1886; El Comercio, 1888).

Se realizó una activa propaganda tanto dentro como fuera del país, acudiendo enfermos y turistas, se promovió el alquiler de casas en el barrio e incluso se puso de moda que muchas parejas pasaran su luna de miel en los altos de Bella Vista (Quesada, en Trejos, 1959). En efecto, para inicios del siglo XX ya tenía un gran atractivo como paseo y sitio de recreación, tal y como las fotografías y tarjetas postales de la época lo evidencian (p.ej. 1909 y en la década del veinte del siglo XX; Gómez, 2004; Castro y Castro, 2005), al grado de que un libro de geografía mundial, editado en París, las menciona como una particularidad (Cortambert, 1909).
La construcción de este primer balneario a nivel nacional es bastante peculiar para ese entonces y para el lugar (Fig. 4). Su arquitectura, si bien ecléctica constructivamente hablando -la fábrica parece hacer sido de bahareque y el resto en madera industrializada-, por lo que puede catalogarse de "victoriana", en cierto sentido más bien con una influencia de New Orleans. En el edificio sobresale por su galería perimetral y su decoración stick style, con material de cubierta galvanizada - un detalle de avanzada para la época- y sobre todo en la torreta que culmina el volumen principal (Andrés Fernández, com. escrita, 2011). El afamado hotel, desgraciadamente fue destruido en 1910 a raíz de los terremotos de Cartago.

Se determina como el balneario termal, entendido como una industria de ocio y terapéutica, se desarrolla en Costa Rica a modo de un turismo doméstico a finales del siglo XIX, muy probablemente debido a la influencia de las tendencias similares europeas (p.ej. en España, ver Rodríguez, 2000), merced entre otros factores, al desarrollo de una clase burguesa -con sus implicaciones económicas y socioculturales- y a la poca abundancia de recursos farmacológicos de probada eficacia. Mientras que el culto al trabajo se avivó con el industrialismo, incrementándose incluso las jornadas laborales hasta prácticamente atentar contra la salud, por otro lado esta concepción del trabajo hace que el ocio se transforme en un placer de tipo elitista o burgués (ver Quesada, 2010).

Regresando a los volcanes costarricenses, hay comentarios aislados sobre sus fuentes termales. En el libro escrito por Pablo Biolley en idioma francés (1889) Costa-Rica et son Avenir, traducido al inglés y al alemán en 1890 por Helmuth Polakowski y por Cecil Charles, respectivamente, fue distribuido en varios países de Europa y publicado parcialmente en Costa Rica en el diario El Maestro. Allí se describe que el Irazú muestra siempre signos de su actividad en el flanco norte bajo la forma de fuentes termales y solfataras.

Con respecto al volcán Poás y el lago contenido en el cráter se indican varios aspectos sobre la actividad (Biolley, 1889):

En la cumbre del Poás se encuentra un pequeño lago cuyas aguas de color azul tranquila y encantadoramente bañan sus 


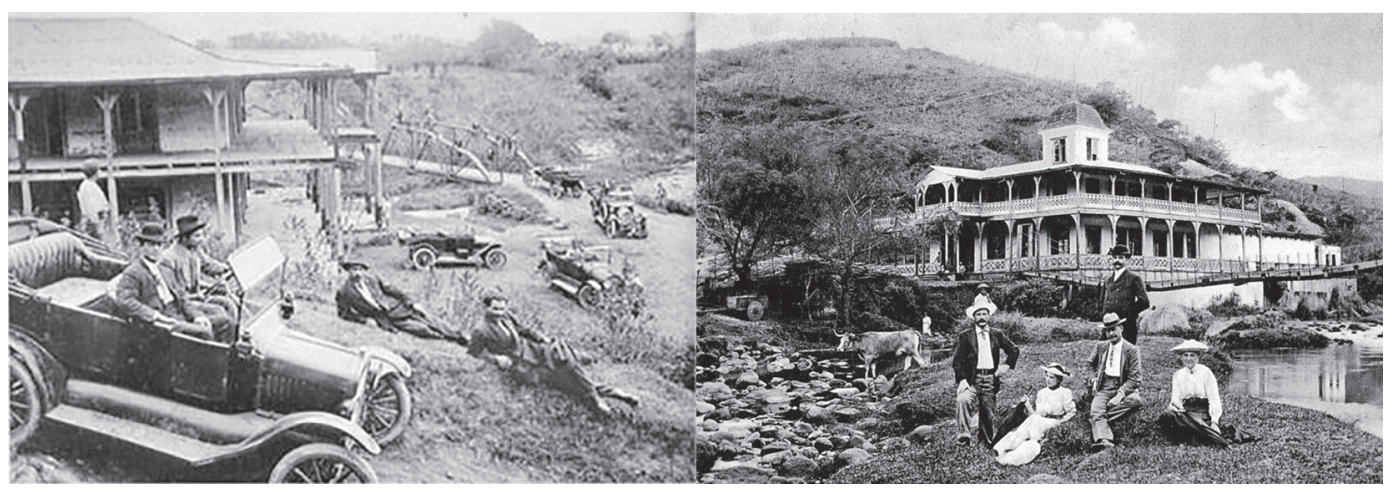

Fig. 4: Diferentes tomas históricas del primer hotel y balneario termal de Costa Rica, el Bella Vista o Baños Termales de Aguacaliente (1886 - 1910) localizado al sur de Cartago. El hotel se encontraba en Hervidero, a 3,5 km al sur de Cartago, en lo que hoy es la entrada a la Ciudad de los Niños, donde solo quedan en pie parte de sus cimientos. Fotografía de fuente desconocida.

orillas. Este es un cráter antiguo. Muy cerca de este se encuentra otro cráter, en cuyo fondo hierve continuamente un agua sucia con fuerte contenido de ácido sulfúrico. Cuando el volcán se encuentra en un período de fuerte actividad se levanta una columna de agua de color oscuro por unos instantes desde el mencionado lago. Grandes burbujas de gas acompañan este acontecimiento. La columna de agua cae lentamente mientras que del fondo del volcán se puede percibir un sostenido sonido ronco. La erupción de este geyser [sic] es uno de los espectáculos más hermosos, que uno puede apreciar, solo que dicho fenómeno no se repite siempre con la misma fuerza. Después del último terremoto de 1888 se observó dicho acontecimiento de la mejor manera. Uno pudo constatar en efecto para este tiempo que la columna de agua alcanzó una altura de $70 \mathrm{~m}$.

Por otro lado, en el apartado de las riquezas minerales en Costa Rica se describen varias fuentes termales muy conocidas en la segunda mitad del siglo XIX (Biolley, 1889):

Casi en todo el país se encuentran fuentes termominerales. Las más famosas son las de Aguacaliente, a tres kilómetros de la ciudad de Cartago, para cuyo

aprovechamiento se formó una sociedad anónima bajo el nombre de "Compañía Bellavista”. Esta sociedad trabaja fervorosamente en la edificación de uno de los balnearios más modernos y mejor acondicionados y en un hotel que deberá ofrecer todas las comodidades para los viajeros y los enfermos. Los análisis del agua de Aguacaliente llevados a cabo por el químico Dr. CF. Chaudler en Nueva York en setiembre de 1887, han generado los siguientes resultados.

Cloruro de sodio

Bicarbonato de lítio

Bicarbonato sódico

Bicarbonato de magnesio

Bicarbonato de calcio

Bicarbonato de barita

Bicarbonato de estroncio

Bicarbonato de hierro

Bicarbonato de cobre

Bicarbonato de manganeso

Sulfato de potasa

Sulfato sódico

Ácido fosfórico

Ácido bórico

Ácido arsénico

Ácido alumínico

Ácido silícico

Materia orgánica

Suma
61,2922

trazas

15,1568

13,0165

56,0627

0,2624

trazas

1,3588

trazas

trazas

2,5775

37,7258

0,1108

1,7669

trazas

0,1166

3,6157

trazas

193,0627 
Las cantidades representan granos y los análisis realizados están referidos a una cantidad de agua que equivale a un galón de los Estados Unidos, cuyo contenido equivale a 231 pulgadas cúbicas. Existen aún muchos otros sitios con fuentes termominerales; las más conocidas después de las de Aguacaliente son las de Orosi, ubicadas en la misma región que las mencionadas y las de Salitral cerca de San José.

Biolley (1911) también menciona la fuente termal de Guacalillo, en el flanco SSW del Barva. Montero (1892) en su libro de Geografía de Costa Rica, comenta lo siguiente:

...pero lo que más llama hoy la atención es el hermoso edificio para baños, situado sobre una fuente termo-mineral de las más famosas, el cual atrae una afluencia constante de personas curiosas ó (sic) enfermas que dan animación extraordinaria al lugar.

Además comenta que las fuentes localizadas cerca de San Marcos, a orillas del Parrita, pueden ser potenciales para desarrollar una industria balnearia, al igual que la existente en Agua Caliente de Cartago.

Posteriormente, monseñor Thiel también tuvo la curiosidad de ir explícitamente a visitar la fuente de El Salitral en Santa Ana, un 30 de enero de 1895 (Herrera, 2009) evidenciando su importancia relativa para la región.

Varios exploradores mencionarían fuentes termales aisladas en el flanco pacífico de la cordillera de Talamanca, entre ellos von Frantzius (1873), Pittier (1895) y unos misioneros alemanes en 1900, en donde nos transmitirían como aportes valiosos sus usos, temores y mitos asociados con el termalismo.

Tal y como se dijo al inicio, a finales del siglo XIX le tocó el turno a un nuevo grupo de civiles como los de la llamada "Generación del $88^{\circ}$ o del "Olimpo", quienes se encargarían de controlar la política del país en las tres primeras décadas del siglo XX. La composición de la nueva clase gobernante la conformaron en su mayoría abogados y políticos profesionales, emparentados con las grandes familias cafetaleras y con medianos productores emergentes, que tuvieron aspiraciones e inquietudes intelectuales y creyeron fielmente en la democracia y el evolucionismo institucional (Castillo, 2009). Sin embargo, dentro de este marco, la primera mitad del siglo XX trajo varios golpes a la economía y estabilidad socio-económica y política del país. El costo de los productos se eleva a partir de 1917 y en general la moneda sufre una devaluación entre 1917 y 1919, disparada por la Primera Guerra Mundial (1914 - 1917), que cambió considerablemente las condiciones monetarias $-\mathrm{y}$ lo que ello trae consigo- en todo el mundo, con un marcado empobrecimiento de la población entre 1914 y 1920 (Barrantes et al., 2005). Después llegan los años duros de la depresión mundial, particularmente entre 1931 y 1934 (Botey, 2005), la llegada de la Segunda Guerra Mundial (1939 - 1945) y la Revolución Nacional (marzo - mayo 1948). Resulta probable que de manera directa o indirecta todos estos hechos no favorecieron al desarrollo de las investigaciones sobre el termalismo durante la primera mitad del siglo $\mathrm{XX}$, en donde existían otras prioridades a nivel nacional e individual.

No es sino hasta bien el siglo XX, en que tenemos una de las primeras menciones, descrita de manera escueta por Romanes (1912), quien comenta que el mismo tipo de roca es encontrado en varias canteras en Agua Caliente a casi dos millas al sur de Cartago:

En este lugar como su nombre lo indica, aparecen manantiales calientes; estos surgen a través de la roca caliza, altamente cargados con materia calcárea la cual es depositada alrededor como sinter.

Fernández (1914) presenta información sobre algunas fuentes identificadas por él cuando realizó un ascenso al volcán Miravalles, si bien no agrega análisis químicos. 
Para 1917, Francisco M. Núñez, escritor y periodista de Desamparados, menciona en su librito "Mi Tierra Nativa" (reproducido en facsímile en los setentas) la fuente termal de San Antonio de Desamparados:

El 'Salitral' y el 'Cerro de don Matías' son dos de las únicas alturas dignas de tomarse en cuenta; al pie de la primera existe una fuente termal, cuyas aguas gozan de crédito entre los vecinos, de tener grandes cualidades curativas, muy especialmente para el reumatismo. También está allí el salitral, terreno hoy de la Municipalidad, antes del vecindario de San Antonio y Patarrá,..." (Núñez, 1917, p. 52).

Los depósitos de travertino de la fuente termal La Calera, por el río Machuca, fueron utilizados para producir cal, que se utilizó en la construcción de una iglesia, al parecer la de San Ramón (quizás en el año 1924?), aunque se desconocen más detalles.

Tristán (1921), igualmente describe las solfataras, hornillas, fuentes y lagunas termales en la falda pacífica del Rincón de la Vieja, sobre la base de anotaciones y dibujos realizados por él en 1903 en el sector de Hornillas.

Trejos Hermanos (1916, 1947), también mencionan la fuente termal de San Antonio de Desamparados, la de Santa Ana y Aguacaliente de Cartago, agregando las del flanco norte del Irazú, las hornillas de Miravalles y la del puente sobre el río Parrita, cerca de San Marcos, si bien no aportan detalles adicionales.

Posteriormente, Schaufelberger (1931) describe seis fuentes termales (valores de sulfatos, cloruros, carbonatos, residuo seco, grados de dureza, temperatura y olor) localizadas en el costado sur del Valle Central (Salitral de Santa Ana, San Antonio de Desamparados, Orosi, Pozo Tibio y Salitral de Pejiballe e interpreta su origen por causas tectónicas relacionadas con una de las fallas del "horts" de Talamaca. Agrega además datos de temperaturas y de residuos secos para la una fuente localizada cerca de una calera en el valle del río Machuca, cerca del cerro llamado Picacho del Mondongo. Comenta que:

la alta temperatura de la mayoría de estas fuentes no es una demostración exacta de sus componentes de origen volcánico; en cada lugar aumenta la temperatura de la tierra con la profundidad, generalmente para cada c/d $34 \mathrm{~m}$ un grado centígrado (grado geotérmico).

Los comentarios de Schaufelberger no solo son novedosos, sino de avanzada y muchos de ellos en sus bases conceptuales, aún válidos. Discute que existen fuentes termales y minerales producto de la infiltración de aguas de lluvia; aguas provenientes de reacciones químicas con el magma, es decir juveniles y finalmente aguas que son mezclas de estos dos grupos, que sería a su criterio el caso de la mayoría de las aguas de Costa Rica. Concluye que una buena parte de estas fuentes termales provienen de una profundidad de unos $850 \mathrm{~m}$ o menos, utilizando una fórmula simple para obtener el dato de la profundidad de donde teóricamente se calentarían las aguas. Reescribiendo la fórmula se tendría que:

$$
\mathrm{Tft}-\mathrm{Tpaa} \cdot 34 \mathrm{~m} /{ }^{\circ} \mathrm{C}=\mathrm{P}
$$

Donde Tft es la temperatura de la fuente termal, Tpaa es la temperatura promedio anual del aire, cuyo valor de la resta se multiplicaría por el gradiente geotérmico normal, que para ese entonces se consideraba que por cada $34 \mathrm{~m}$ de profundidad, la temperatura subía un grado centígrado, para dar con ello la profundidad de calentamiento del agua. Esta sería con seguridad la primera fórmula de un geotermómetro, aunque se desconoce si se atribuye a Schaufelberger o a otros científicos precedentes (p.ej. H. Keller en Suiza). Agrega que los ácidos y las sales de potasio y de sodio proceden del agua juvenil magmáticas, mientras que las sales (bicarbonatos, sulfatos y cloruros) de calcio, magnesio e hierro fueron disueltos de los estratos de calizas o areniscas de las rocas de 
lo que antiguamente se llamaba el Terciario, hoy Paleógeno y Neógeno. Comenta, además, que los feldespatos se pueden transformar en arcillas y por lixiviación del hierro debido a los ácidos, en caolines y que algunas vetas de caolín en las faldas del Tablazo pueden ser restos de antiguas fuentes termales de origen volcánico y que las actuales fuentes termales se encuentran más abajo producto de movimientos tectónicos más recientes.

Un año después agrega, sin dar más detalles, una serie de fuentes termales (aparte de las ya mencionadas por él en 1931) en las de las faldas de los volcanes Rincón de la Vieja, Miravalles, Poás (laguna Caliente y San Miguel de Sarapiquí), Barva (Huacalillo, Esmeralda, Varablanca y Santa Clara) e Irazú. También incluye otras en las faldas de los Montes del Aguacate, tales como la calera del valle del Machuca (ya mencionada en 1931), la de San Pablo de Turrubares y los hervideros al NE de Esparta en el valle del Barranca (Schaufelberger, 1932a). Igualmente, llega a publicar sus investigaciones a nivel internacional (Schaufelberger, 1932b, 1933).

Otra observación histórica de este investigador, es que piensa que algunos de los temblores en Costa Rica son el resultado del colapso de cavernas como producto de la lenta y permanente disolución de las rocas por medio de las aguas termales, dejando con ello cavidades (Schaufelberger y Jiménez, 1933). Aunque existen casos históricos al respecto, del colapso de cavernas y la generación de un evento sísmico menor asociado, es la excepción más que la regla.

Segura y León (1940) mencionan las fuentes termales enclavadas al pie del cerro Bermejo. Dóndoli (1949) por su parte presenta un informe preliminar sobre las fuentes de Agua Caliente de Cartago (reproducido en 1970) e incluye un cuadro comparativo de diversos autores y laboratorios de los valores químicos. Reafirma lo dicho por Schaufelberger en el sentido que dicha fuente y posiblemente la de Orosi, brotan de una misma línea de fractura o falla con dirección NW-SE.

En los albores del siglo XX, las aguas minerales frías de Salitral de Santa Ana gozaban de gran uso popular medicinal por los campesinos de la región. Trejos Hermanos (1916) recalcan que sus excelentes propiedades medicinales son muy semejantes a la Apollinaris (Alemania), al grado que se aprovechan sus aguas e incluso se exportan. En efecto, alrededor de la naciente de agua se le construyó una infraestructura, que según una antigua placa bautizaba dicho lugar con el nombre "La Fuente" en correspondencia con los años 1914 - 1962 (ver Kupiec, 1962).

\section{LAS INVESTIGACIONES CIENTÍFICAS MODERNAS CON FINES COMERCIALES Y APLICADOS A LA INGENIERÍA: 1955 - PRESENTE}

Esta etapa está caracterizada por estudios más sistemáticos, modernos, con análisis estandarizados, incluyendo isótopos, con el fin de explotar en sus inicios el agua mineral o soda, evaluar principalmente el potencial de generación de energía eléctrica a partir del potencial de vapor generado en un campo geotérmico y, posteriormente, estudios orientados a la vigilancia volcánica, así como fines geoturísticos, volviéndose una industria generalizada a lo largo y ancho del territorio nacional. Todo lo anterior coincide con una estabilidad social, económica y política, con un gran desarrollo industrial, tecnológico y en infraestructura, además de la salud y educación mediante la creación de más de 50 universidades, dentro de lo que se puede denominar la "Era de la Cibernética" (sociedad de la información y conocimiento). Muchos lugares, típicamente rurales y agropecuarios, se transformaron en urbano-rurales y urbanos en todo el sentido de la palabra, dándose procesos de transformación sorprendentes en todo el país.

Ya se había hablado de la importancia que tenía la fuente mineral fría de Salitral de Santa Ana desde mediados del siglo XIX, pero no es sino hasta en 1954 en que otorgó el permiso y en 1955 cuando se instaló la primera empresa embotelladora de aguas minerales que se conoce en el país, fundada por don Antonio Ortega, denominada "Las Piedras", con una construcción de madera en la margen derecha del río Salitral (Kupiec, 1962). La planta embotelladora contaba con 5 personas en su planilla, llegándose a empacar diariamente 18 botellas de un litro, 27 botellas de medio litro y 
30 botellas de un cuarto de litro (Figs. 5 y 6). Las botellas llevaban por nombre en su cara principal "Agua Mineral Natural AO" -abreviaciones del nombre del empresario-, y en su parte trasera, la palabra "Soda". La planta al parecer dejó de funcionar en 1963 (R. Azofeifa, com. verbal, 2010) y el permiso para embotellar agua se canceló el 30 de agosto de 1977.

Antiguamente, en las noches de luna llena de marzo, se formaban grupos para visitar la fuente mineral, a cuya agua le agregaban naranja agria y azúcar, o sirope mientras tocaban guitarra y cantaban.

Los primeros reconocimientos para evaluar el posible desarrollo y aprovechamiento de la energía geotérmica en Costa Rica se realizaron entre 1959 y 1964 por los expertos (en su mayoría geólogos) Fritz Dürr, D.F. Bailley, Gunnar Bodvarsson y James Healy, promovidos por las Naciones Unidas, recomendándose principalmente las faldas de los volcanes Rincón de la Vieja y Miravalles, por lo que presentaron informes técnicos al respecto (Healy, 1964, 1969; Faillace, 1973; Vides y Umaña, 1974). Este es el punto de inicio de las investigaciones geotérmicas modernas a nivel nacional propiamente dichas (Alvarado, 2000). Con la crisis del petróleo y el auge de las energías alternativas, se celebró en Pisa en 1970, el Simposio de las Naciones Unidas sobre la energía geotérmica. Esta problemática fortalecerá la financiación de las investigaciones geotérmicas a nivel nacional.

Contemporáneamente, la Facultad de Farmacia de la Universidad de Costa Rica -con la colaboración del Departamento de Química- promovieron una serie de investigaciones orientadas a las propiedades químicas, físicas y curativas con sus posibles usos farmacéuticos de varias fuentes termales de Costa Rica, mediante la realización de proyectos de investigación y de tesis, particularmente entre 1960 y 1962 (Delgado, 1960; Harley, 1960; Montagné, 1961; Camacho, 1962; Ching Fong, 1962; Kupiec, 1962), incluyendo algunos cuadros comparativos. Estos trabajos de tesis fueron continuados por Gómez (1972), quien comenta que en Marina de San Carlos, la "Sociedad Centro Turístico Aguacaliente de San Carlos Ltda.", -posteriormente llamado "El Tucano"-, existe desde 1969 para aprovechar dichas nacien- tes que ya gozaban de un gran atractivo por los vecinos de ciudad Quesada, con fines de entretenimiento o por atributos para paliar las enfermedades de artritis, reumatismo, sinusitis y bronquitis, entre otras. Estos estudios corresponderían a lo que hoy día se denomina Hidrología Farmacéutica a nivel mundial. El naciente Club de Montañeros de Costa Rica aporta, por su parte, un detalle preliminar en su boletín de 1967 sobre estas fuentes termales en las márgenes del río San Rafael, por San Carlos (Goicoechea y Mena, 1991).

Waring (1965) incluye en su libro fuentes termales de Costa Rica con datos de ubicación y temperatura: 39 fuentes minerales y termales agrupadas en 35 regiones. Aunque no resulta sencillo realizar una comparación, se puede concluir con excepción de 8 fuentes, la mayoría de los manantiales citados por Waring (1965) están contenidas en los trabajos de von Frantzius (1862a, b, 1873). También incluye una de uso recreacional llamada Ojo de Agua, localizada $5 \mathrm{~km}$ al sur de Alajuela, que aunque menciona que es caliente, debe de corresponder con la que aún hoy día se conoce como el balneario de Ojo de Agua, que no es ni mineral ni termal. Sin embargo, Waring (1965) al hacer su titánico trabajo titulado "Thermal Springs of the United States and Other Countries of the World - A Summary", posiblemente nunca visitó personalmente las fuentes termales costarricenses, sino que se basó en los trabajos existentes y en sus traducciones, por lo que pudo mal interpretar y hasta entremezclar varias de ellas, dando con ello localizaciones erróneas.

Sáenz (1971) realizó el tercer catálogo de fuentes termominerales en Costa Rica (el primero fue realizado por von Frantzius en 1862a, b) y las ubican espacialmente, trabajo que fue actualizado posteriormente por Saénz y Barquero (1983). Sin embargo, tan solo aportan un valioso listado de nombres y ubicaciones aproximadas, sin ningún detalle físico-químico ni geológico (Cuadro 2).

Faillace (1973) complementa unas notas sobre algunas fuentes termominerales en Guanacaste, dentro del marco de un proyecto de investigación de aguas subterráneas en tres áreas seleccionadas de Costa Rica. Estos estudios fueron complementados por una serie de investigaciones con fines específicamente geotérmicos, realizados por el 


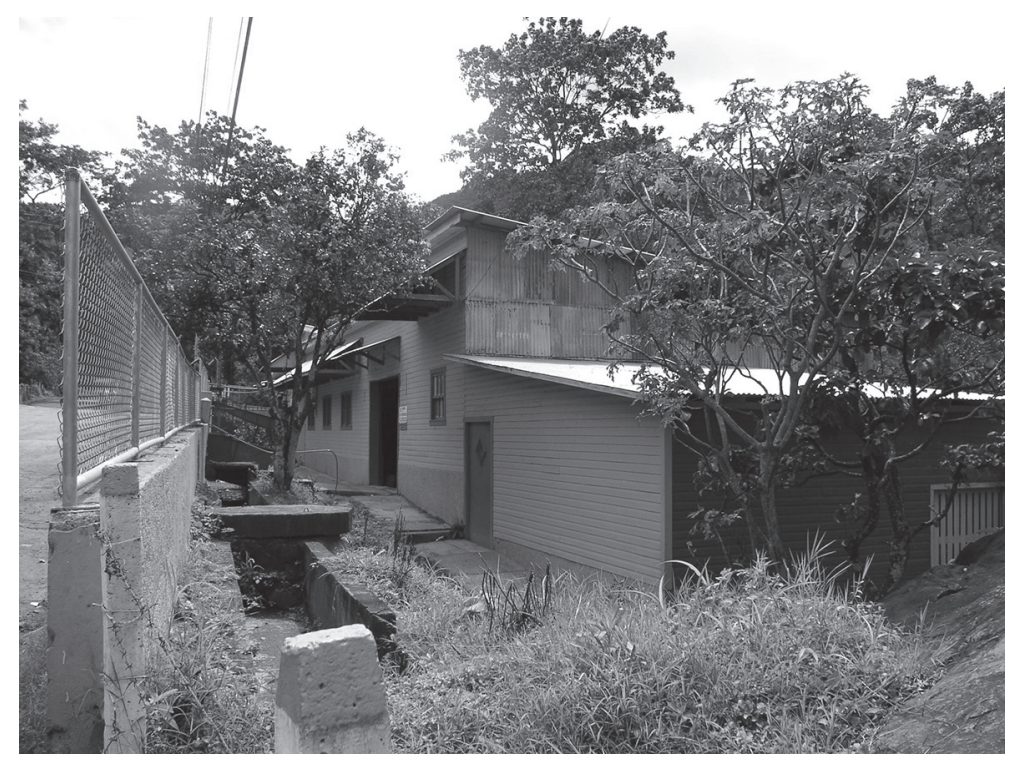

Fig. 5: Edificio donde se ubicó la planta embotelladora de agua mineral Las Piedras (1955 - 1963) en Salitral de Santa Ana.

Instituto Costarricense de Electricidad, que en primera instancia estuvieron concentrados en la cordillera de Guanacaste (Corrales, 1974, 1976; Mainieri y Corrales, 1977; ICE, 1977; Giggenbach y Corrales, 1992; Yock, 1998; Kempter y Rowe, 2000), si bien después se extendieron a otras regiones del país con el fin de evaluar su potencial de un modo integral y su eventual explotación a corto, mediano y largo plazo. Particularmente, en 1988 - 1989, el ICE realizó un nuevo estudio de reconocimiento del potencial para el futuro aprovechamiento de la energía geotérmica de todo el territorio nacional, tomándose muestras de la mayoría de las fuentes termales (ICE-ENEL, 1989, 1990) o realizando estudios específicos (Vargas, 2001; Rodríguez, 2002).

Como contraparte geográfica de los detallados estudios en Guanacaste, algunas fuentes termominerales del Valle Central fueron investigadas, aportándose su clasificación y se identificaron las características geológicas asociadas con ellas (ICE, 1977; Paniagua y Van der Bilt, 1979; Gómez, 1981; Boschini, 1988). Gómez (1981) y posteriormente Cotter (1985), analizan el potencial de las aguas minerales (principalmente termales) en Costa Rica con el fin de utilizarlas como bebida natural embotellada, sin embargo, concluyen que se requieren de más estudios para una factibilidad económica al respecto.

Igualmente, en las últimas dos décadas del siglo $\mathrm{XX}$, los estudios de las fuentes minerales $\mathrm{y}$ termales toman dos nuevos rumbos aplicados. Uno hacia la vigilancia volcánica y estudio detallado de los lagos cratéricos, particularmente en los volcanes Poás (Casertano et al., 1985; Brantley et al., 1987; Rowe et al., 1995; Sanford et al., 1995), Arenal (Bigot y Barquero, 1986, Barquero, 1989; Marini et al., 1990; Lopez et al., 1995, 2006; Soto et al., 1995, 1999) y Rincón de la Vieja (Kempter y Rowe, 2000), tan solo para citar algunos. Otro asunto de gran interés tecnológico aplicado fue el resolver problema de las aguas ácidas y su agresividad, ya sea hacia los cementos y tuberías subterráneas de conducción, como fue el caso del entonces proyecto Hidroeléctrico Toro 2 (Rojas et al., 1990, 1992) o hacia tratar de neutralizar y así aprovechar el vapor ácido de elevada temperatura en el Campo Geotérmico Miravalles (Moya y Nietzen, 2010). Estos estudios fueron realizados por nacionales con soluciones tecnológicas propias, reconocidas y aplaudidas a nivel internacional.

Con excepción del antiguo hotel de Aguacaliente de Cartago, que fue dañado por el 


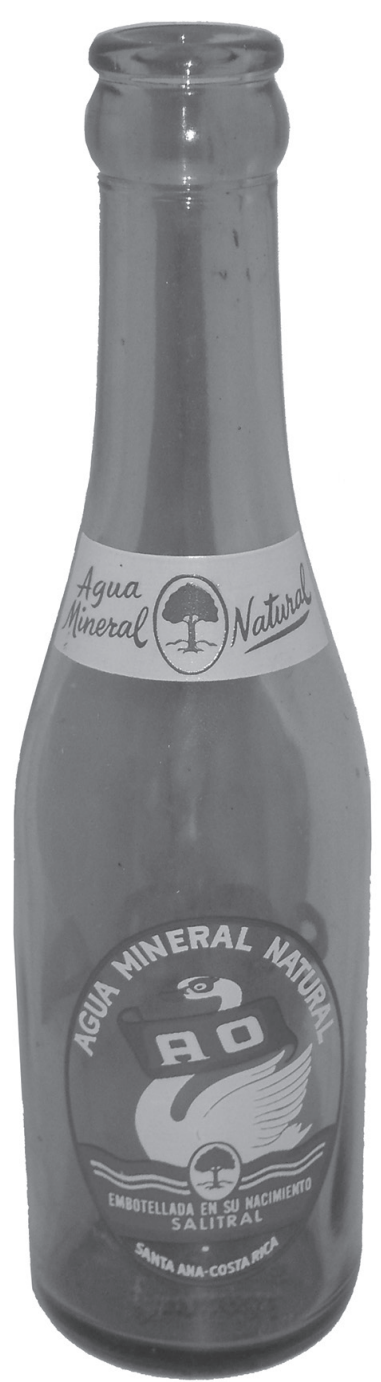

Fig. 6: Botella utilizada para embazar el agua mineral de Salitral de Santa Ana.

terremoto de Cartago de 1910, no es sino hasta la década de los sesentas del siglo pasado en que aparecen algunos balnearios aprovechando las aguas termales, pero en su mayoría para un público local o a lo sumo nacional, estableciéndose un turismo doméstico: el Balneario de Aguas Termales de Orosi (1960), el Balneario Los Patios (1966; Fig. 7) y el Centro Turístico Aguacaliente de San Carlos (1969). Este último, posteriormente constituyó un fallido "Country Club" y a partir de diciembre de 1987 se estableció como un activo complejo turístico y hotelero, originalmente de 2 estrellas, a lo que hoy corresponde con el Hotel Occidental El Tucano y Spa. Así los costarricenses aprovechaban su tiempo libre (particularmente los domingos y días feriados), para visitar con la familia estos balnearios en los famosos paseos dominicales.

Sin embargo, la mayor explotación de las aguas termales se vendría a desarrollar en los alrededores del volcán Arenal, constituyéndose en un punto de referencia (landmark) a nivel nacional y a su vez un semillero en ideas para aquellos que le siguieron en otras regiones del país. Aproximadamente, a partir de 1985, se comenzó a aprovechar de modo rústico el agua termal del río Tabacón, en La Fortuna de San Carlos, pero serían varios hechos los que fomentarían lo anterior, entre ellos, la finalización de la recesión económica mundial de los ochenta (1980 - 1983), el mejoramiento de la vía de acceso a La Fortuna y al volcán Arenal a partir de 1985, la Ley 6990 de Incentivos para el Desarrollo Turístico (15 de julio de 1985), y la obtención del Premio Nobel de La Paz por parte del entonces presidente de Costa Rica, don Óscar Arias en 1987, entre otros hechos. Así, Costa Rica se dio a conocer a nivel mundial como un país de paz, sin ejército, con una biodiversidad y paisajes muy variados en distancias cortas, bajo una bandera ambientalista, al grado que a partir de 1993 el turismo pasó al primer lugar en cuanto a ingresos (ver Bundschuh et al., 2007; Quesada, 2010). Lo anterior fue en parte disparado por la relativa estabilidad socioeconómica de Costa Rica, en donde paulatinamente se fueron mejorando el estado de la red vial (además de diferentes medios de transporte), luz, agua potable, teléfono, internet, aeropuertos, sanidad, ornato, educación, entre otros. Todo ello hace del país un caleidoscopio de posibilidades constituyéndose en un gran imán para el turismo, ya no solo nacional sino extranjero, promoviendo las aguas termales un turismo de placer, salud y naturalista. El conjunto de servicios ofrecidos creció substancialmente (Bundschuh et al., 2007; Quesada, 2010). Incluso, en el marco de la Feria Mundial de Turismo de Londres (2007), se le distinguió a Costa Rica como el mejor destino ambiental 


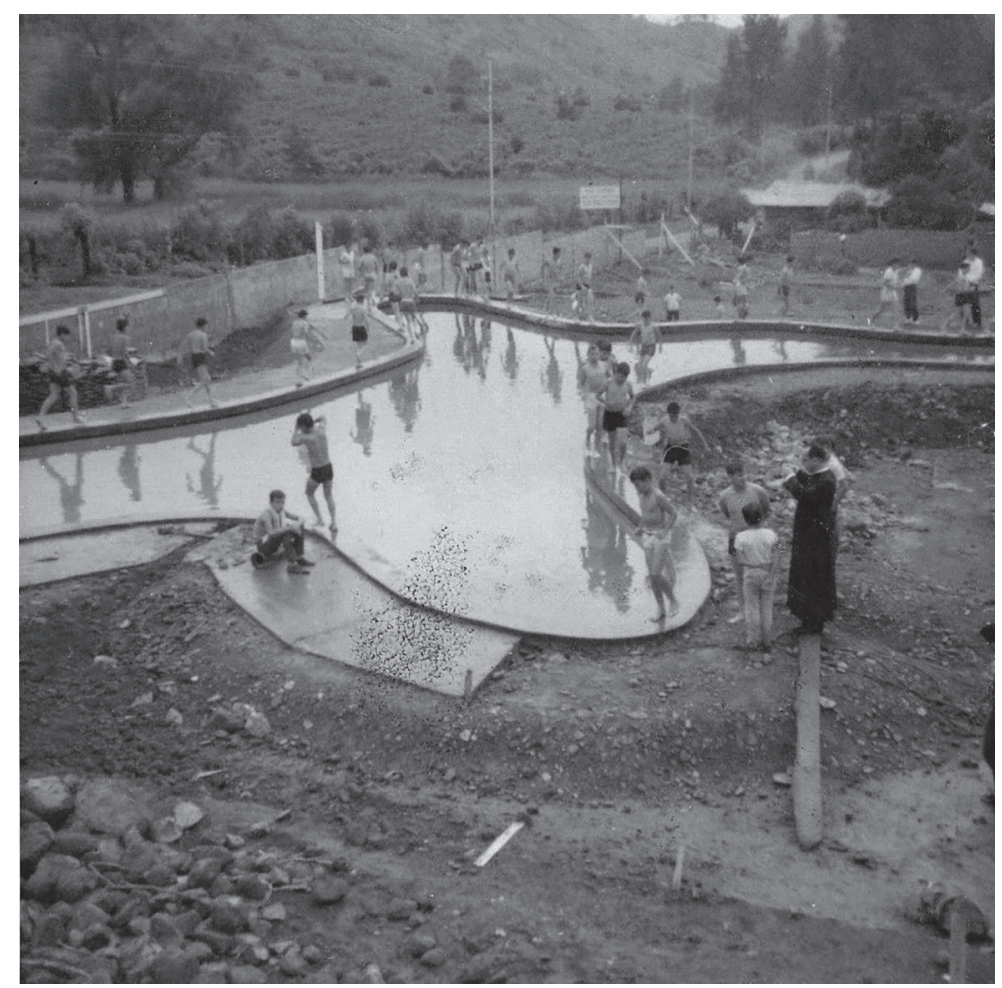

Fig. 7: Balneario Los Patios, Orosi de Cartago, en construcción y uso en setiembre de 1969 (cortesía de Adrián Mora A.).

de América Latina y en el periodo 2000 - 2007, Costa Rica fue el país de América Central más visitado como destino turístico (Quesada, 2010).

Se dieron periodos con bonanzas, que permitieron que no solo las clases altas, sino prácticamente todos los niveles de la clase media, dispusieran en algún momento de tiempo y dinero suficiente para el ocio. Lo anterior ha dado origen a vacaciones en los diversos balnearios y sus servicios como un lugar idóneo con precios que varían dentro de un amplio rango. Estos cambios han puesto de manifiesto el carácter dúctil del balneario, siendo más ecléctico cuánto más próspero sea como industria y su entorno natural lo favorezca.

Así, lo anterior se dio primero en La Fortuna a partir de 1990 -pero luego en otros lugares de Costa Rica-, una de las transformaciones más importantes, que es cuando el campesino y ganadero, dedica parte de sus terrenos a restaurantes, sodas, tiendas de souvenir, cabinas y hoteles. Se inicia así una nueva industria y un cambio drástico de un pueblo de rural a urbano, aprovechando a todo tipo de turistas, desde el de ingresos bajos (el llamado "mochilero" y la clase baja) hasta el acomodado o incluso multimillonario, reflejándose en una diferenciación en el tipo de servicios, particularmente el hospedaje, desde las cabinas rústicas hasta los hoteles 5 estrellas. Este proceso continuó a lo largo de toda la primera década del nuevo siglo, cambiando drásticamente, por ejemplo, la fisonomía de La Fortuna y sus alrededores, no solo en lo que corresponde a la infraestructura y servicios turísticos en general, sino además incluyendo la clínica del Seguro Social, clínicas privadas, cuatro agencias bancarias, aeropuerto para aviones pequeños, además del tipo y calidad de las viviendas.

El ejemplo de desarrollo de La Fortuna para captar turismo extranjero y nacional con sitios lujosos, spas, hoteles 3 a 5 estrellas y turismo de aventura y ecológico, fue seguido por otras regiones como San Rafael de San Carlos al pie del volcán Platanar, los alrededores de volcanes y parques Nacionales Rincón de la Vieja y 
Cuadro 2

Catálogos y números de fuentes minerales y termales a través del tiempo. En la actualidad, el número de fuentes termales identificadas es cercano a 200 .

\begin{tabular}{ccc}
\hline Autor y año & Número de fuentes & Comentario \\
\hline von Frantzius (1862a, b, 1873) & $28^{*}$ & Primeros catálogos y primer libro, aunque sin mapas \\
Waring (1965) & 39 & Segundo catálogo con mapa y referencias \\
Sáenz (1971) & 43 & Primer catálogo por un nacional, pero sin referencias \\
Mainieri \& Corrales (1977) & 54 & Actualización con énfasis en Guanacaste \\
Sáenz \& Barquero (1983) & 72 & Actualización de la lista de Sáenz (1971) \\
ICE-ENEL (1989), ICE & 125 & Primer trabajo con listados geoquímicos, localizaciones geográficas, \\
(1990) & & temperatura, pH y texto explicativo \\
\hline
\end{tabular}

*Este es el número total de fuentes termales y minerales individuales, dado que en cada catálogo, su número varió.

Miravalles, e incluso las Juntas de Abangares y por el río Navarro. Allí se establecieron resorts (estaciones de descanso y recreo, hoteles vacacionales) y lodges (hospedajes de campo). Nuevos sitios recreacionales, pero todavía con desarrollo rústico, se encuentran en la zona Sur (Cuadro 3). Varios complejos balnearios con sus hoteles y otros servicios compiten en el ostentar el primer lugar como complejo termal más grande de Costa Rica, entre ellos The Spring Resort y Spa y Baldi Thermae, ambos en cerca de La Fortuna de San Carlos, volcán Arenal, así como el Centro Turístico Thermo Manía, en las faldas del volcán Miravalles, entre otros.

Mientras que los balnearios termales establecidos a partir de 1960 responden a un estilo relativamente simple, con piscinas rectangulares, áreas de pastos bien recortados y un predominio de lo horizontal, dirigido a un público nacional y con fines de esparcimiento o recreación por unas cuantas horas, la mayoría de los balnearios termales presentan a partir de 1990 no solo un incremento dramático en su número, sino además en sus estilos arquitectónicos, tipo de servicios y variedad del público. Se rompe con los esquemas tradicionales de la geometría poligonal simple por estilos más variados (curvilíneos) debido a la incorporación de modelos foráneos, producto de la globalización, tratando de integrar el contexto ecoturístico, aprovechando la geología (fumarolas, hornillas, volcanes de lodo, charcas humeantes, grandes rocas) y la geografía (cauces, pozas, cascadas, desniveles naturales y el bosque primario o secundario), para incorporarlo dentro del ambiente, o incluso creando un paisaje artificial con plantas exóticas y nativas, rocas ornamentales, puentes, senderos, piletas artificiales, todo mimetizándose con el medio.

Suelen proveer además en su interesado eclecticismo, no solo las piscinas termales con diferentes temperaturas, sino también el hospedaje (hoteles, cabinas, cabañas), restaurantes, bares húmedos, lagunas, jacuzzis, saunas y baños turcos naturales y artificiales, spas con terapias básicas (barros volcánicos, piedras calientes, algas, tratamientos faciales, masajes, etc.). Sin lugar a dudas, por lo que la mayoría de los costarricenses y extranjeros asocian a las fuentes termales, no es tanto por sus propiedades terapéuticas, sino por sus aspectos recreativos y relajantes, es decir una verdadera expresión del ocio.

Aunque es algo prematuro de analizar, se puede deducir que los balnearios pre-1990 siguen las tendencias arquitectónicas y de cambio que ocurrieron en todo el país. Obedecen a un periodo de asimilación del legado moderno y contextualización de valores histórico-culturales, incluyendo las particularidades del sitio, orientado al llamado "estilo internacional" que nos da una interpretación más pragmática y comercial. De 1990 al presente, se desarrollan los procesos de globalización contra la búsqueda de contextualización, concebidas fuera de nuestras fronteras, cuya significación sigue un criterio de mercado-imagen. Se dan extremos y entre ellos hibridaciones en el campo arquitectónico entre el regionalismo crítico 
Cuadro 3

Número de lugares principales con balnearios termales y otras facilidades (hospedaje, dormida, etc.).

\begin{tabular}{cc}
\hline Lugar & Número \\
\hline Flancos volcán Rincón de & 5 \\
la Vieja & \\
Flancos volcán Miravalles & 10 \\
Flancos volcán Arenal & 15 \\
Cordillera de Tilarán & 5 \\
La Marina-La Palmera & 7 \\
Río Toro & 1 \\
Valle del Guarco-Orosi & 4 \\
Zona Sur y La Cangreja & 5 \\
Total & 52 \\
\hline
\end{tabular}

(modernidad que contextualiza las tradiciones, el contexto natural y la memoria colectiva) y el posmodernismo (tendencia revisionista que intentaba regresar a las raíces de la cultura), todo dentro de procesos de internacionalización con expresiones particulares (Vives, 1998).

Los balnearios termales, aunque nacieron en Costa Rica como un turismo de placer, recreo o descanso, después se comenzaron a promover como un tipo de turismo de salud o de bienestar. Sin embargo, pese al gran desarrollo de los balnearios turísticos termales, no existe una verdadera política ni orientación balneoterapéutica, de hidrología médica o farmacéutica y mucho menos el concepto de vacaciones terapéuticas por periodos de varias semanas, bajo la orientación de expertos y con varias fases de tratamiento. En su mayoría se restringe al disfrute de las aguas termales y frías, de los barros volcánicos, las piedras calientes y los masajes dentro del concepto de spa, pero por un periodo de media hora a varias horas, no dentro de un plan regulado a mediano o largo plazo y bajo la supervisión de un especialista. De igual modo, se abandonaron los estudios pioneros iniciados por la Escuela de Farmacia sobre hidrología farmacéutica y no está dentro de su plan de estudios en ninguna de las Escuelas o Facultadas universitarias (Medicina, Farmacia, Química ni
Geología) orientado a la salud, con excepción de los análisis bacteriológicos y geoquímicos que se enseñan y realizan para decidir si las aguas son potables o no, o con fines industriales o si su geoquímica indica posibles campos geotérmicos para producir energía eléctrica a partir del vapor.

La explosión geoturística del termalismo y spas en Costa Rica en los últimos años, no va del todo paralelo con la creciente importancia por estas como terapias complementarias a nivel mundial.

Hasta la mitad del siglo pasado, los tratamientos en los spa, incluyendo el uso de las aguas termales en tratamientos externos (hidroterapia y balneoterapia), así como el barro medicinal (geoterapia), fueron muy populares, pero tendieron a declinar en los países anglosajones (pobladores escandinavos, británicos, estadounidenses y canadienses) con el desarrollo de efectivos analgésicos, viéndose los spas termoterapéuticos con escepticismo y como una práctica alternativa no ortodoxa. Por el contrario, la balneoterapia y los spas poseen una alta credibilidad médica como tratamiento y está soportada por universidades e instituciones en la mayoría de los países de la Europa del sur y del este (Francia, Alemania, Italia, España, República Checa), en Asia (Japón, Israel) y Sudamérica (Brasil, Chile), bajo el control médico ortodoxo, como una medicina complementaria o auxiliar, no alternativa. Los analgésicos, a pesar de su poder, no siempre logran eliminar el dolor y los efectos adversos y hasta secundarios, ha motivado de nuevo a volver la vista hacia la terapia de los spa. En 1986, la Organización Mundial de la Salud aceptó a las aguas termales como una herramienta alternativa para gozar de buena salud física y mental. La OMS es el organismo dependiente de la Organización de la Naciones Unidas que tiene a su cargo el estudio epidemiológico, planificaciones sanitarias y evaluaciones terapéuticas de grandes núcleos de población en todo el mundo, en especial de los países en desarrollo. El consejo ejecutivo de la OMS ha decidido establecer relaciones oficiales con la Federación Internacional de Termalismo Climatismo (FITEC) 
y ha admitido oficialmente el tratamiento hidrotermomineral válido como tal y coadyuvante de múltiples afecciones (Rodríguez, 2000; Bender et al., 2005; Fernández-González et al., 2010, 2011; Gutenbrunner et al., 2010; Oláh et al., 2010; Fioravanti et al., 2011, entre muchos otros).

\section{CONCLUSIONES}

La descripción e investigación de las fuentes termales después de la colonización fue producto de un entusiasmo espureo traído por investigadores extranjeros, por lo que no existió una búsqueda y descripción sistemática. La mayoría de documentos relacionados con la descripción de las fuentes termales se publicaron luego de 1855 , con el impulso de un grupo de investigadores principalmente europeos y norteamericanos. Las cinco etapas de reconocimiento e investigación acá planteada tienen períodos de tiempo distintos, definidos por el nivel de bienestar económico de los conglomerados sociales cercanos a las fuentes termales.

Gran cantidad de referencias y documentos consultados se encuentran dispersos en varios centros de documentación nacionales e internacionales. Aquí se revisaron más de 70 documentos que mencionan o describen algunas de las fuentes termales. Sin embargo, no existe una recopilación sistemática de dichos documentos y es de esperar que cada vez aparezcan más textos e información sobre alguna fuente termal ya descrita o recién descubierta. Sobre esto se está trabajando.

A pesar que el reconocimiento de las fuentes termales se inició hace más de un siglo y de que en Costa Rica existen casi 200 fuentes termales identificadas, continúa siendo muy escaso el conocimiento integral y accesible sobre las características físico- químicas y las eventuales propiedades terapéuticas. Su aprovechamiento ha sido principalmente recreativo en balnearios y los estudios sobre su utilización terapéutica se abandonaron, tales como las investigaciones pioneras iniciados por la Escuela de Farmacia de la UCR sobre hidrología farmacéutica. La balneoterapia, la geoterapia, la hidrología médica y la hidrología farmacéutica no están dentro del plan de estudios en ninguna de las Escuelas o Facultadas universitarias (Medicina, Farmacia, Química ni Geología). Esto se podría deber a la falta de credibilidad de algunas escuelas de ciencias médicas modernas y a la falta de conocimientos referente a las tendencias recientes en algunos países sobre los beneficios complementarios aportados a la salud por parte de los baños termales. No ha existido una verdadera política ni orientación en estos campos y mucho menos el concepto de vacaciones terapéuticas por periodos de varias semanas, bajo la orientación de expertos y con varias fases de tratamiento. Al menos no se visualiza dentro de un plan regulado a mediano plazo y bajo la supervisión de especialistas. Quizás ello pueda ser un punto para meditar sobre la necesidad de implementar cursos de capacitación, el contemplarlo dentro del plan curricular formal del sistema de estudios universitarios y el fomentar de nuevo investigaciones dirigidas sobre el tema.

\section{AGRADECIMIENTOS}

Muchas personas e instituciones han contribuido a que esta investigación llegara a feliz término, cuya lista es grande. Se agradece los comentarios de un revisor anónimo.

\section{REFERENCIAS BIBLIOGRÁFICAS}

Alvarado, G. E. (2000). Los volcanes de Costa Rica: su geología, historia y riqueza natural (2a ed.). San José: EUNED.

Alvarado, G. E. y Morales, L. D. (1989). Historia de la vulcanología en Costa Rica. En A. Ruiz y L. Camacho (eds.), Historia de la Ciencia y la tecnología: el avance de una disciplina (pp. 291-314). Cartago: ETCR. 
Attwood, G. (1882). On the Geology of a part of Costa Rica: With an appendix by W.H Hudleston. Quaterly Journal of the Geology Society, 38, 328-336.

Barquero, R. (1989). Estudio geoquímico preliminar de fuentes termales y frías del volcán Arenal. Boletín del Observatorio Vulcanológico del Arenal, 2(3), 38-55.

Barrantes, C. (2009). El último cacique. Talamanca, siglo XIX. San José: EUNED.

Barrantes, E. A., Bonilla, H. M. y Ramírez, O. M. (2005). Costo y condiciones de vida: La canasta de subsistencias en Costa Rica, 1914-1920. En R. J. Viales (ed.), Pobreza e historia en Costa Rica (pp. 101-154): Editorial Universidad de Costa Rica.

Bender, T., Karagülle, Z., Bálint, G. P., Gutenbrunner, C., Balint, P. V. y Sukenik, S. (2005). Hidrotherapy, balneotherapy, and spa treatment in pain management. Rheumatology International, 25, 220-224.

Bigot, S., y Barquero, J. (1986). Estudio hidrogeoquímico del volcán Arenal, contribución a la actividad eruptiva. Boletín de Vulcanología, 17, 7-14.

Biolley, P. (1889). Costa-Rica et son Avenir. Traducido por Charles, C. (1890). Costa Rica and her future. Washington: Judd y Detweiller.

Biolley, P. (1911). Un manantial interesante. Boletín del Fomento, Ministerio de Fomento, 1 (5), 17-21.

Blanco, A. (1989). Reseña histórica de la medicina en Costa Rica desde la Conquista hasta el siglo XIX. En A. Ruiz y L. Camacho (eds.), Historia de la ciencia y la tecnología: el avance de una disciplina (pp. 375402). Cartago: ETCR.
Boschini, I. (1988). Informe geoquímico de las aguas termales del sureste del Valle Central. San José: ICE. Informe Interno.

Botey, A. M. (2005). Las representaciones sociales de la pobreza en la Costa Rica de la década de 1930. En R. J. Viales (ed.), Pobreza e historia en Costa Rica (pp. 273 295): Editorial Universidad de Costa Rica.

Brantley, S. L., Borgia, A., Rose, G., Fernández, J. F. y Reynolds, J. R. (1987). Poás volcano crater lake act as a condenser for acid metal-rich brine. Nature, 330(6147), 470-472.

Bundschuch, J., Birkle, P., Finch, R., Day, M., Romero, J., Paniagua, S., . . Chaves, D. (2007). Geology-related tourism for sustainable development. En J. Bundschuh y G. Alvarado (eds.), Central America: Geology, Resources and Hazards (Vol. 2, pp. 1014-1098): Taylor y Francis.

Camacho, O. L. (1962). Análisis físico, químico y posibles aplicaciones médico farmacéuticas del agua de la fuente termo-mineral de "Aguacaliente", Cañas-Guanacaste (Tesis de licenciatura inédita), Universidad de Costa Rica, San José, Costa Rica

Casertano, L., Borgia, A., Cigolini, C., Morales, L. D., Montero, W., Gómez, M. y Fernández, M. (1985). Investigaciones geofísicas y características geoquímicas de las aguas hidrotermales: volcán Poás, Costa Rica. Geofísica Internacional, 24(2), 315-332.

Castillo, A. (2009). La guerra del oro. Tierra y minería en Abangares: 1890-1930. San José: Editorial Universidad de Costa Rica.

Castro, Á., y Castro, C. (2005). Costa Rica, imágenes e historia. Fotografias y Postales 1870-1940. San José: Gestión Empresiarial S.A. para Universidad Latinoamericana de Ciencia y Tecnología. 
Ching Fong, A. (1962). Investigación química del contenido del agua procedente de la fuente termal de Hervideros, San Ramón, provincia de Alajuela. (Tesis de licenciatura inédita). Universidad de Costa Rica, San José, Costa Rica.

El Comercio. (1888). Los baños de Agua Caliente. El Comercio, 27(VI).

Corrales, R. (1974). Avance del informe de la visita a los campos geotermales en Guanacaste. San José: ICE. (Informe Interno).

Corrales, R. S. (1976). Proyecto Geotérmico de Guanacaste; Informe de previabilidad técnica: geoquímica. San José: ICE. Informe interno.

Cortambert, E. (1909). Curso de Geografía. Traducido por F. Corona. París: Librería de Hachette y C, Montrouge.

Cotter, G. (1985). Aguas minerales de Costa Rica: evaluación y perspectivas. Tecnología en marcha, 8(1), 3-9.

De La Cruz, V. (2005). Pobreza y lucha social en Costa Rica, 1870-1930. En R. J. Viales (ed.), Pobreza e historia en Costa Rica (pp. 5369): Editorial Universidad de Costa Rica.

De La Haya, D. (1723). La actividad del volcán Irazú en 1723 [manuscrito]. Revista Geografía América Central, 4, 203-210.

Delgado, E. (1960). Investigación del Ccontenido mineral del agua procedente de la fuente termal de Aguacaliente (Tesis de licenciatura inédita), Universidad de Costa Rica, San José, Costa Rica

Dóndoli, C. (1949). Informe geológico preliminar sobre las fuentes de "Agua Caliente". Informes técnicos y notas geológicas Dirección de Geología, Minas y Petróleo, 3, 8-11.
Faillace, C. (1973). Notas sobre algunas fuentes termo minerales en Guanacaste. Publicaciones Geológicas del ICAITI, IV, 47-58.

Fernández, D. L. (1889). Historia de Costa Rica: durante la dominación española 1502 1821. Madrid: Tipografía de Manuel Ginés Hernández.

Fernández, L. (comp.) (1907). Colección de documentos para la Historia de Costa Rica. Barcelona: Imprenta Viuda de Luis Tasso.

Fernández, R. (1914). Ascensión al volcán Miravalles. Boletín de Fomento, IV(3), 160-171.

Fernández-González, M. V., Gámiz, E., Saura, I. y Delgado, R. (2010). La Hidrología farmacéutica como materia docente de los estudios de farmacia. Trabajo presentado en el III Congreso Internacional de Educación Superior de Ciencias Farmacéuticas (EDUSFARM). Granada, España.

Fernández-González, M. V., Gámiz, E., Saura, I. y Delgado, R. (2011). La Hidrología Farmacéutica como materia docente de los estudios de Farmacia. Recuperado de http://farmacia.ugr.es/ars/

Fioravanti, A., Cantarini, L., Guidelli, G. M. y Galeazzi, M. (2011). Mechanisms of action of spa therapies in rheumatic diseases: what scientific evidence is there? Rheumatology International, 31(1), 1-8. doi: 10.1007/s00296-0o7-0358x

Gaceta Oficial de Costa Rica. (1861). Gaceta Oficial de Costa Rica, $\mathrm{N}^{\circ} 11$ (1 de junio de 1861).

Gagini, C. (1917). Los aborígenes de Costa Rica. San José: Tip Trejos Hnos. 
Giggenbach, W. F. y Corrales, R. (1992). Isotopic and chemical composition of water and stream discharges from volcanicmagmatic-hydrothermal systems of the Guanacaste Geothermal Province, Costa Rica. Applied Geochemistry, 7, 309-332.

Goicoechea, C. y Mena, W. (1991). Las fuentes termales de Agua Caliente de San Carlos. Cavernas de Costa Rica, Anthros-GEA, 7, $1-14$.

Gómez, J. de L. (1981). Aguas minerales naturales (Tesis de licenciatura inédita). Universidad de Costa Rica, San José, Cosdta Rica.

Gómez, M. (2004). Costa Rica en fotografías antiguas. San José: Jadine.

Gómez, V. (1972). Algunas propiedades fisicas y químicas del agua de la fuente termal "Aguacaliente de San Carlos" (Tesis de licenciatura inédita). Universidad de Costa Rica, San José, Costa Rica.

Gutenbrunner, C., Bender, T., Cantista, P. y Karagülle, Z. (2010). A Proposal for a Worldwide Definition of Health Resort Medicine, Balneaology, Medical Hydrology and Climatology. International Journal of Biometeorology, 54, 495-507.

Hale, J. (1826). Six Months Residence and Travels in Central America through the free states of Nicaragua and particularly Costa Rica. En R. Fernández (ed.), Costa Rica en el siglo XIX; Antología de viajeros. San José: EUNED.

Harley, M. (1960). Análisis físico-químico de la fuente termal de Guacalillo (Tesis de licenciatura inédita). Universidad de Costa Rica, San José, Cosdta Rica.

Healy, J. (1964). Geothermal Resources of the Guanacaste Range, Costa Rica. San José: ICE. Informe interno.
Healy, J. (1969). Notas sobre los volcanes de la Sierra Volcánica de Guanacaste, Costa Rica. IGN Informe Semestral, 37-47.

Herrera, A. I. (2009). Monseñor Thiel en Costa Rica: visitas pastorales 1880-1901. San José: Editorial Tecnológica de Costa Rica.

Hilje, L. (2008). El valle de Orosi, explorado por Alexander von Frantzius. Revista Comunicación, 17(1), 80-103.

ICE. (1977). Proyecto Geotérmico de Guanacaste, Informe de previabilidad técnica: Rogers Engineering y Geothermex. Informe interno.

ICE-ENEL. (1989). Estudios de reconocimiento y prefactibilidad geotérmica en la Republica de Costa RIca, Fase I. Estudio de reconocimiento. Informe Final Proyecto COS/83/ t01/a/71/99. Anexos 1 y 2, 485. San José: ICE-ENEL. Informe interno.

ICE-ENEL. (1990). Estudios de reconocimiento y prefactibilidad geotérmica en la Republica de Costa Rica. Fase II: Estudio de prefactibilidad del área de Tenorio. Informe interno de sintesis RCO-D 7821/Rev. 1. PFT 104: Proyecto COS/83/T01. Informe Geovulcanológico, Mapa Geológico. Instituto Costarricense de Electricidad Ente Nazionale per L'Energia Electrica, ELC, Geotermia Italiana, Geossysem (Costa Rica-Italia), proyecta COS/83/t01, diciembre 1989. Pisa, Italia. Informe interno.

Jara, C. V. y García, A. (2003). Diccionario de mitología bribri. San José: Editorial Universidad de Costa Rica.

Kempter, K. A. y Rowe, G. L. (2000). Leakage of active crater lake brine through the north flank at Rincón de la Vieja volcano, northwest Costa Rica, and implications for crater collapse. Journal of Volcanology and Geothermal Research, 97, 143-159. 
Kupiec, D. (1962). Análisis químico de las aguas minerales procedentes de la fuente ubicada en Salitral de Santa Ana, provincia de San José (Tesis de licenciatura inédita). Universidad de Costa Rica, San José, Costa Rica.

La Nación. (20 de enero de 1959). Es indiscutible la propiedad de la Municipalidad de Cartago sobre las fuentes de Agua Caliente. La Nación, p. 8.

López, D. L. y Smith, L. (1995). Fluid flow in fault zones: Analysis of the interplay of convective circulation and topographically driven groundwater flow. Water Resources Research, 31(6), 1489-1503.

López, D. L., Bundschuh, J., Soto, G. J., Fernández, J. F. y Alvarado, G. E. (2006). Chemical evolution of thermal springs at Arenal Volcano, Costa Rica: Effect of volcanic activity, precipitation, seismic activity and Earth tides. Journal of Volcanology and Geothermal Research, 157, 166-181.

Mainieri, A. y Corrales, M. (1977). Localización de fuentes termales y volcanes. San José: ICE. Informe interno.

Marini, L., Guido, M., Fernández, J. F. y Barquero, R. (1990). Análisis geoquímico de las fuentes termales y frías del volcán Arenal. Boletín Observatorio Vulcanológico del Arenal, 3(6), 9-27.

Marr, W. (1863). Reise nach Central-Amerika. [Traducido por Reinhold, I.]. En J. C. Solórzano (ed.), Viaje a Centroamérica (pp. xvi + 472). San José: Editorial Universidad de Costa Rica.

Mata, J. (1930). Monografía de Cartago. Cartago: Imprenta El Heraldo.

Meagher, T. F. (1859-1860). Holidays in Costa Rica. Harper's New Monthly Magazine.
New York: Harper y Brothers, Publishers: diciembre: 18-38, enero: 145-164 y febrero: 304-325. En R. Fernández (ed.), Costa Rica en el siglo $X X$ : antología de viajeros (pp. 273-379): EUNED. Y en J. C. Vargas (ed.), Tropical Travel: The Representation of Central America in the Nineteenth Century; Facsimiles of Illustrated Texts (1854-1895): Editorial UCR

Meléndez, C. (1974). Viajeros por Guanacaste (Vol. 4). San José: Imprenta Trejos Hnos.

Meléndez, C. (1976). Carl Hoffmann. Viajes por Costa Rica (Vol. 6). San José: Imprenta Nacional.

Meléndez, C. (1983). Historia de Costa Rica (2 $2^{\mathrm{da}}$ ed.). San José: EUNED.

Meléndez, C. y Arrea, F. (2010). La Colonia, economía y Sociedad. En V. De La Cruz (ed.), Historia Ggeneral de Costa Rica (Vol. 3, pp. 163). San José: Grupo Nación S.A.

Montagné, R. (1961). Análisis químico del agua procedente de la fuente termal "El ojito", Orosi (Tesis de licenciatura inédita). Universidad de Costa Rica, San José, Costa Rica.

Montero, F. (1892). Geografia de Costa Rica. Barcelona: Tip. Lit de José Cunill Sala.

Mora, R. (2001). Hot springs of Damas, Quepos. Informe privado inédito.

Moya, P. y Nietzen, F. (2010). Performance of calcium carbonate inhibition and neutralization systems for production Wells at the Miravalles Geothermal Field. Trabajo presentado en el Proceedings World Geothermal Congress 2010. Bali, Indonesia.

Núñez, F. M. (1917). Mi tierra nativa. Estudio histórico, geográfico y estadístico del cantón de Desamparados. San José: Sociedad Editora Nacional. 
Oláh, M., Konez, Á., Fehér, J., Kálmánczhey, J., Oláh, C., Balagh, S., . . . Bender, T. (2010). The effect of balneotherapy on C-reative protein, serum cholesterol, triglyceride, total antioxidant status and HSP-60leves. International Journal of Biometeorology, 54, 249-254.

Paniagua, S. (2000). Aguas termales. En P. Denyer y S. Kussmaul (eds.), Geología de Costa Rica (pp. 443-456). Cartago: Editorial Tecnológica.

Paniagua, S. y Van Der Vilt, H. (1979). Fuentes termales del Valle Central, Costa Rica. Ciencia y Tecnología, 3, 109-129.

Peraldo, G. y Montero, W. (1994). Temblores del periodo colonial de Costa Rica. Cartago: ETCR.

Pittier, H. (1895). Informes de Instrucción Pública correspondientes a los años de 1892-93 y 1893-94. San José: Tipografía Nacional.

Platt, L. (1865). Examen analítico de cuatro fuentes de agua mineral de Costa Rica. La Gaceta Oficial, 23(IX), 1-2.

Polakowsky. (1890). Costa Rica una seine Zukunft von Paul Biolley. Berlin: Kommision Verlag und Druck von Thorman y Goetsch.

Quesada, M. Á. (2001). Entre silladas y rejoyas. Viajeros por Costa Rica. Cartago: Editorial Tecnológica de Costa Rica.

Quesada, R. (2010). Elementos de turismo: teoría, clasificación y actividad ( $2^{\mathrm{a}}$ ed.). San José: EUNED.

Quirós, J. S. (2002). Diccionario EspañolChorotega, Chorotega-Español. San José: Editorial Universidad de Costa Rica.

Rodríguez, A. (2000). Evolución de la terapéutica balnearia: Un espacio interdisciplinar. En J. A. López y J. L. Pinuaga (eds),
Panorama actual de las Aguas Minerales y Minero-medicinales en España (pp. 87102). España: Instituto Tecnológico GeoMinero de España.

Rodríguez, A. (2002). Informe del levantamiento geoquímico del área geotérmica Pocosol. San José: ICE. Informe interno.

Rojas, L., León, C., Vega, O. L., Estrada, J. y Fernández, J. F. (1990). Estudio de la caracterización físico-química de las aguas naturales en la cuenca alta del río Toro y su influencia con las obras del proyecto. San José: ICE. Informe interno.

Rojas, L., León, C., Vega, O. L., Rivera, A., Fernández, J. F. y Estrada, J. (1992). Seguimiento al carácter físico-químico de las aguas naturales y selección de un cemento apropiado. San José: ICE. Informe Interno.

Romanes, J. (1912). Geology of a part of Costa Rica. Quaterly Journal of the Geology Society, 68, 103-139.

Rowe, G., Brantley, S., Fernández, J. y Borgia, A. (1995). The chemical and hydrological structure of Poás Volcano, Costa Rica. Journal of Volcanology and Geothermal Research, 64, 233-267.

S, A. (1886). Aguas Termales de Cartago, Costa Rica. San José: Imprenta de José Canalías.

Sáenz, R. (1971). Aparatos volcánicos y fuentes termales de Costa Rica. Dirección de Geología, Minas y Petróleo. Informes técnicos y Notas geológicas, 41, 1-16.

Sáenz, R. y Barquero, J. (1983). Fuentes termominerales de Costa Rica. Boletín de Vulcanología, 13, 12-17.

Sanford, W., Konikow, L., Rowe, G. y Brantley, S. (1995). Groundwater transport of craterlake brine at Poás Volcano, Costa Rica. 
Journal of Volcanology and Geothermal Research, 64, 269-293.

Schaufelberger, P. (1931). El origen de las fuentes termales y minerales de la Meseta Central. Revista El Maestro, V(9), 227-232.

Schaufelberger, P. (1932a). La escuela costarricense. San José: Secretaría de la Educación Pública.

Schaufelberger, P. (1932b). Über einige Mineral und Thermalquellen von Costa Rica. Eclogae Geologicae Helvetiae, 25(1), 139162.

Schaufelberger, P. (1933). Über einige MIneral und Thermalquellen von Costa Rica. Eclogae Geologicae Helvetiae, 26(2), 281-294.

Schaufelberger, P. y Jiménez, E. (1933). Apuntes de Geología 7: algunas nociones sobre terremotos y temblores en Costa Rica. San José: Imprenta La Tribuna.

Segura, A. y León, A. (1940). El valle de Cartago y Coris. Revista Departamento Nacional de Agricultura (DNA), 5(9-12), 438-449.

Sierra, O. (1987). Mitos y leyendas de Costa Rica: El Sacrificio del rualdo. La Nación.

Soto, G. J., López, D., Fernández, F. y Alvarado, G. E. (1995). Caracterización geoquímica de las aguas termales del volcán Arenal (Costa Rica) dentro de su marco geovulcanológico. Trabajo presentado en el $V$ Congreso Nacional de Recursos Hídricos.

Soto, G. J., López, D., Fernández, F. y Alvarado, G. E. (1999). Caracterización geoquímica de las aguas termales del volcán Arenal (Costa Rica) dentro de su marco geovulcanológico. Boletín OSIVAM, 11(21-22), 1-20.

Trejos, Hnos. (1916). Geografía Ilustrada de Costa Rica. San José: Tipografía de Trejos Hermanos.
Trejos, Hnos. (1947). Geografía ilustrada de Costa Rica. San José: Tipografía de Trejos Hermanos.

Trejos, J. F. (1959). Geografía de Costa Rica. Física, política y económica. San José: Imprenta Universal.

Tristán, J. F. (1921). Apuntes sobre el Volcán Rincón de la Vieja. Revista de Costa Rica, II(7), 193-206.

Vargas, A. G. y Kussmaul, S. (2015). Consideraciones sobre el primer libro de Fuentes termales en Costa Rica. Revista Geológica América Central, 53, 47-59.

Vargas, A. y Alvarado, G. E. (2007). Los primeros catálogos de fuentes termales en Costa Rica realizados por el naturalista alemán, el Dr Alexander von Frantzius en 1862 y 1873. Revista Geológica América Central, 37, 11-22.

Vargas, J. R. (2001). Geología, hidrogeoquímica y modelo conceptual del reservorio para prefactibilidad del campo geotérmico Pocosol, San Ramón-San Coarlos, Costa Rica (Tesis de maestría inédita). Universidad de Costa Rica, San José, Costa Rica.

Vides, A., y Umaña, J. E. (1974). Informe sobre visita a unos campos geotermales de los volcanes Rincón de la Vieja y Miravalles, cordillera de Guanacaste. San José: ICE. Informe Interno.

Vives, I. (1988). Una arquitectura para el cambio. In F. Fonseca y J. E. Garnier (Eds.), Historia de la Arquitectura en Costa Rica (pp. 383-361): Fundación Museos del Banco Central de Costa Rica.

Von Frantzius, A. (1860). Das Ehemalige Missionkonvent Orosi bei Cartago in Costa Rica. Das Ausland, 50(1180-1185) y 51, 1209-1214. 
Von Frantzius, A. (1861). Beiträge zur Kenntniss der Vulkane Costa Rica's. Petermann's Geographische Mittheilungen Helt IX y Helt X, Gotha: Justus Perthes, 5, 329-338 y $6,381-385$.

Von Frantzius, A. (1862a). Die warmen Mineralquellen in Costa Rica (Schluss). Preussiche Medicinal Zeitung, 5(14-16), 124-126. [Traducido por Vargas, A. G., y Kussmaul, S. (2007). Las fuentes termominerales en Costa Rica I. Revista Geológica América Central, 37, 23-30].

Von Frantzius, A. (1862b). Die warmen Mineralquellen in Costa Rica. Berlin: Editorial A. W. Schade.

Von Frantzius, A. (1869). Der südöstliche Theil der Republik Costa Rica. Mittheilungen aus Justus Perters' Gregraphischer Anstalt über wichtige neue Erforschungen auf dem Gesammtbebiete der Geographie, Gotha: Justus Perthes, 15(9), 323-330.

Von Frantzius,A.(1873). Die warmen Mineralquellen in Costa Rica. Neues Jahrbuch Für Mineralogie, Geologie and Paläontologie, 5, 496-510. [Traducido por Vargas, A. G. y Kussmaul, S. (2007). Las fuentes termominerales en Costa Rica II. Revista Geológica América Central, 37, 31-34].

Von Seebach, K. (1865a). Reise durch Guanacaste (Costa Rica), 1864 und 1865. Petermann's
Geographische Mittheilungen Helt IX y Helt X, Gotha: Justus Perthes, 7(2), 241-249. [Reproducido por Meléndez, C. (1974). Viajeros por Guanacaste. Ministerio de Cultura, Juventud y Deportes Dpto de publicaciones].

Von Seebach, K. (1865b). Besteigung des Vulkans Turrialba in Costa Rica. Mittheilungen aus Justus Perthes' Geographischer Anstalt über wichtige neue Erforschungen auf dem Gesammgebiet der Geographie. Gotha: Justus Perthes, 9, 321-324.

Wagner, M. (1862). Über einige wenig bekannte Vulkane im trophischen Amerika. Mittheilungen aus Justus Perthes' Geographischer Anstalt über wichtige neue Erforschungen auf dem Gesammtgebiete der Geographie. Petermanns Geographische Mitteilungen, 8, 408-420.

Waring, G. A. (1965). Thermal Springs of the United States and Other Countries of the World. A summary: Geological Survey Professional Paper

Yock, A. (1998). Chemical and isotopic studides in the Miravalles Geothermal Field, Costa Rica. Geothermal Training Programme, 17, 461-499.

Zeledón, E. (1989). Leyendas Costarricenses. Heredia: Museo de Cultura Popular. 